\title{
CD44, hyaluronan, the hematopoietic stem cell, and leukemia-initiating cells
}

\author{
Margot Zöller* \\ Department of Tumor Cell Biology, University Hospital of Surgery, Heidelberg, Germany
}

\section{OPEN ACCESS}

Edited by:

David Naor,

Hebrew University of Jerusalem, Israel

Reviewed by:

lan Dransfield,

University of Edinburgh, UK

Tracy Robson,

Queen's University Belfast, UK

Ursula Günthert,

University Hospital Basel, Switzerland

*Correspondence:

Margot Zöller,

Department of Tumor Cell Biology,

University Hospital of Surgery, Im

Neuenheimer Feld 365, Heidelberg

D69120, Germany

m.zoeller@uni-hd.de

Specialty section:

This article was submitted to Inflammation, a section of the journal Frontiers in Immunology

Received: 01 February 2015 Accepted: 30 April 2015

Published: 26 May 2015

Citation:

Zöller M (2015) CD44, hyaluronan, the hematopoietic stem cell, and leukemia-initiating cells. Front. Immunol. 6:235. doi: 10.3389/fimmu.2015.00235
CD44 is an adhesion molecule that varies in size due to glycosylation and insertion of so-called variant exon products. The CD44 standard isoform (CD44s) is highly expressed in many cells and most abundantly in cells of the hematopoietic system, whereas expression of CD44 variant isoforms (CD44v) is more restricted. CD44s and CD44v are known as stem cell markers, first described for hematopoietic stem cells and later on confirmed for cancer- and leukemia-initiating cells. Importantly, both abundantly expressed CD44s as well as CD44v actively contribute to the maintenance of stem cell features, like generating and embedding in a niche, homing into the niche, maintenance of quiescence, and relative apoptosis resistance. This is surprising, as CD44 is not a master stem cell gene. I here will discuss that the functional contribution of CD44 relies on its particular communication skills with neighboring molecules, adjacent cells and, last not least, the surrounding matrix. In fact, it is the interaction of the hyaluronan receptor CD44 with its prime ligand, which strongly assists stem cells to fulfill their special and demanding tasks. Recent fundamental progress in support of this "old" hypothesis, which may soon pave the way for most promising new therapeutics, is presented for both hematopoietic stem cell and leukemiainitiating cell. The contribution of CD44 to the generation of a stem cell niche, to homing of stem cells in their niche, to stem cell quiescence and apoptosis resistance will be in focus.

Keywords: CD44, hematopoietic stem cells, leukemia-initiating cells, bone marrow niche, homing, adhesion, dormancy, apoptosis resistance

\section{Introduction}

CD44, first described as a lymphocyte homing receptor (1), is expressed by a wide range of hematopoietic and non-hematopoietic cells (2). Interest in CD44 increased considerably, when it was noted that the insertion of alternatively spliced exon products in the CD44 standard or CD44 hematopoietic isoform (CD44s) strikingly affects the molecules function, such that expression of CD44 variant isoforms (CD44v) induces a metastatic phenotype in locally growing tumor cells $(2,3)$.

Abbreviations: ASC, adult stem cells; bFGF, basic fibroblast growth factor; BM, bone marrow; BMP, bone morphogenetic protein; BM-Str, BM stroma cells; C, complement; CD44s, CD44 standard isoform; CD44v, CD44 variant isoforms; CIC, cancer initiating cells; ECM, extracellular matrix; ERM, ezrin, radixin, moesin; ESC, embryonic SC; FN, fibronectin; GAG, glucosaminoglycan; GEM, glycolipid enriched membrane microdomains; HA, hyaluronic acid; HAS, hyaluronan synthase; HGF, hepatocyte growth factor; HSC, hematopoietic SC; ICD, intracellular domain; kd, knockdown; ko, knockout; LIC, leukemia initiating cells; MSC, mesenchymal SC; M $\phi$, macrophages; OPN, osteopontin; PCCD4, programmed cell death 4; PDGFR, platelet-derived growth factor receptor; RTK, receptor tyrosine kinase; TGF, transforming growth factor; TPO, thrombopoietin; VEGF, vascular endothelial growth factor; wt, wild type. 
At the time, it was surprising that a leukocyte marker is engaged in solid tumor metastasis formation. As the hematopoietic system is the only organ that components repeatedly shift between sessile and mobile states, we argued that metastasizing tumor cells may transiently take over part of the program of hematopoietic cells and that this programmatic shift, which is independent of oncogene transformation, depends to a considerable degree on CD44 and its activities (4). This hypothesis received strong support by the recovery of cancer- and leukemia-initiating cells (CIC/LIC), which are defined by their capacity to take over part of the program of stem cells (SC). In fact, CD44s/CD44v are CIC/LIC markers $(5,6)$ and, most importantly, CD44 was the first marker defined as a CIC/LIC biomarker. This implies that CD44 is engaged in fulfilling special SC-related tasks in CIC/LIC (7). These particular tasks include, besides growth upon serial transplantation in xenogeneic models, self-renewal and recapitulation of the heterogeneous phenotype of the parental tumor, reflecting the differentiation capacity of CIC/LIC. It also includes, at least for a subset of CIC/LIC, the capacity of SC to transiently shift from a sessile toward a mobile state, which is required for metastasis formation (7-9). Furthermore, like SC, CIC/LIC are highly apoptosis resistant $(6,7)$ and may profit from the crosstalk with the surrounding $(5,6)$. Notably, too, CIC/LIC are heterogeneous (10) and genetically instable (11). This is in line with their disputed, not mutually exclusive origin from adult stem cells (ASC), from oncogene-transformed committed progenitors or from cell fusion particularly with macrophages $(\mathrm{M} \phi)$ (12). Despite their heterogeneous origin, CIC/LIC share many features with hematopoietic SC (HSC), like relative quiescence, longevity, drug resistance, and support by the surrounding that for SC is called the niche. Finally, there is strong evidence that CD44/CD44v is engaged in many of the activities, which CIC/LIC share with ASC (13).

CD44 is a quite abundant expressed molecule. Thus, the question arises, what qualifies CD44 for this multitude of very special tasks. This review outlines that two features of CD44 mostly account for the molecule's contribution to SC maintenance: first and most important, CD44 crosstalks with the surrounding/the niche. Second, CD44 is located in membrane subdomains, which are particularly prone for collecting signal transduction molecules, proteases, and cytoskeletal components, and foster concerted activities. HSC and LIC were chosen as prominent examples. Based on the largely overlapping activities of CD44 in CIC and LIC, some references to CIC are included, as far as deeper insight was gained with the latter.

\section{CD44 Structure and Ligands}

CD44 are glycoproteins encoded by a single gene (14). CD44 molecules vary in size due to $N$ - and $O$-glycosylation $(15,16)$ and insertion of alternatively spliced exon products in the extracellular domains of the molecule (17). The smallest, hematopoietic isoform (CD44s) is present on the membrane of most vertebrate cells (3). CD44 has seven extracellular domains, a transmembrane, and a cytoplasmic domain (18). The latter is encoded by exons 9 or 10 (19). Between domains 5 and 6 up to 10, variant exon products can be inserted by alternative splicing (15).
CD44 is a member of the family of cartilage link proteins (15, 16). The $N$-terminal region forms a globular structure. Conserved cysteins are important for the stability of the extracellular domain, and two cysteins in the flanking region account for correct link domain folding (19). This globular structure contains binding sites (AA 32-132) for collagen, laminin, fibronectin (FN), and cell surface receptors like E-selectin and L-selectin (20-22). Importantly, CD44 also is the major receptor for hyaluronan (HA) (23). HA binds to a basic motif (AA 150-158) within the globular structure, but outside of the link domain $(23,24)$. Though the HA binding motif is present in all CD44 isoforms, not all CD44 ${ }^{+}$cells bind HA. However, HA-binding can be induced by CD44 cross-linking, which indicates that HA-binding depends on conformational changes or a redistribution of CD44 in the cell membrane (25). CD44 also has two binding sites for other glycosaminoglycans (GAG) (26). The $N$-terminal globular domain is followed by a stretch of $46 \mathrm{AA}$, which comprises exon products $5-7$. This stretch of 46 AA forms a stalk like structure (27). It is heavily glycosylated and contains putative proteolytic cleavage sites (28). Variable exon products are inserted in the stalk like region (29). The transmembrane region supports CD44 oligomerisation and contributes to incorporation in glycolipid-enriched membrane microdomains (GEM) (30). The cytoplasmic tail of CD44 contains binding sites for the cytoskeletal proteins ankyrin and ezrin, radixin, moesin (ERM). Ankyrin mediates contact with spectrin and is involved in HA-dependent adhesion and motility (31). ERM proteins are engaged in regulating migration, cell shape, and protein resorting in the plasma membrane (32). The $N$-terminus of activated ERM proteins binds to a motif between the transmembrane region and the ankyrin binding site, and their C-terminus binds to F-actin. Thereby, ERM proteins link CD44 to the actin cytoskeleton (33). Merlin, an additional ERM family member, which lacks the actinbinding domain, might be involved in stabilizing the junctionalcortical actin interface through its $N$-terminal domain (34). The binding of CD44 to cytoskeletal linker proteins influences signaling pathways downstream of CD44, which expands the range of CD44-mediated functions.

Finally, CD44 O-glycosylation, the transmembrane region, and the cytoplasmic tail affect the membrane subdomain localization. Depending on the activation state, CD44 is recruited into GEM (35), which has great bearing on the interaction of CD44 with extracellular ligands and the association with other transmembrane and cytoplasmic molecules $(36,37)$. These associations are most crucial for the accessory functions of CD44 in migration and signal transduction. This is a sequel of the inner membrane side organization of GEM, which favors harboring adapter and signal transducing molecules like src family members (38). Some of these cytoplasmic adapter and signaling molecules are constitutively associated with GEM-located CD44 (39). GEM are also prone for internalization (40).

Unlike CD44s, CD44v is only expressed on subpopulations of epithelial and hematopoietic cells, particularly during embryonic development, hematopoietic cell maturation and activation, and in some carcinoma and leukemia with a tendency toward overexpression in CIC/LIC $(41,42)$. Several of the CD44v exon products can contain specific post-translational modifications. These include a heparan-sulfate site in exon v3, which serves for the 
binding of heparin-binding proteins like basic fibroblast growth factor (bFGF) (43); CD44v6 contains a binding site for hepatocyte growth factor (HGF), vascular endothelial growth factor (VEGF), and osteopontin (OPN) (44-46). OPN also binds to CD44v10 (47). Via these cytokine/chemokine binding sites, CD44v takes over a central and coordinating role in receptor tyrosine kinase (RTK) activation (48).

Briefly, CD44 is the major HA receptor. It has a multitude of additional ligands and associates with transmembrane and cytoplasmic molecules. This is due to several glycosylation sites, variant exon product sequences, the insertion into GEM, and the cytoplasmic tail structure. Noteworthy, HA binding contributes to the GEM recruitment of CD44. Beyond forcing CD44 associations, this has bearing on CD44 internalization.

\section{HSC/LIC CD44 and Stem Cell Genes}

CD44 is a marker of ASC, including HSC and of a large range of CIC and LIC $(7,49)$. In addition, there is some evidence for pronounced CD44v expression in SC (50). Thus, the question arose, whether CD44 is engaged in stem cell gene expression and/or whether CD44/CD44v expression is regulated by stem cell genes.

Embryonic SC (ESC) are characterized by expression of a set of master SC transcription factors, Oct4, Sox2, and Nanog (51), as well as distinct chromatin organization and epigenetic signatures, which govern the intrinsic ability to self renew and to differentiate into multiple lineages (52). Polycomb genes, which have a role in transcriptional repression through histone modification, associate with the promoter and regulatory regions of target genes in ESC. Expression of master gene transcription factors and epigenetic regulation are maintained in $\operatorname{HSC}$ and $\operatorname{LIC}(53,54)$, which share with ESC Oct4, Nanog, and Myc overexpression $(55,56)$, and Notch, Wnt, and Hedgehog signaling pathways, important in shaping tissue structure, cell fate, and identity (57). In fact, leukemia recurrence was prevented by deletion of the polycomb gene Bmil, important for HSC self-renewal (58).

As discussed below in concern of HSC quiescence, there are links between CD44, Nanog, and Myc expression, and CD44 is a target of the Wnt and Notch pathways in HSC and LIC (59-61). However, there is no evidence that CD44 plays a central role in regulating master gene transcription factors in HSC/LIC (62-64).

Besides master SC transcription factors, miRNA were recognized as key regulators of self-renewal and SC fate (65). This includes hematopoiesis, HSC being lost upon abrogation of Dicer, which was ascribed to miR-125a (66). Additional miRNA overexpressed in HSC either promote HSC engraftment (miR-125b-5p, miR-126-3p, miR-155) or are disadvantageous (miR-196b, miR181c, miR-542-5p, let7e) (67). Notably, miRNA profiles differ significantly between HSC and lineage committed progenitors, and miRNA profiles in hematological malignancies differ from those of HSC and progenitor cells. In addition, miRNA profiles are selective for distinct leukemia [review in Ref. (68-72)]. Nonetheless, there are some common trends: miR-15a, miR-29b, miR-34a, miR-151, and miR-204 frequently act as tumor suppressors, and miR-155, miR-96, miR-24, miR-21, miR-32, miR-106-25, and let7 as oncomir (73). However, the engagement of HA/CD44 on
miRNA regulation in HSC and LIC remains to be elaborated in detail. So far, there are only sporadic hints toward a mutual impact.

HA-crosslinked CD44v3 binds Nanog, Oct4, and Sox2, which promotes miR-302 expression (74) a key player in controlling SC self-renewal and pluripotency (75). Also, binding of HER2 to CD44 leads to upregulation of MTA-1 (metastasisassociated-1), which induces silencing of the miR-139 promoter, accompanied by increased CXCR4 expression (76). HA-CD44v6 binding promotes PKCE activation, and this increases Nanog phosphorylation and nuclear translocation, where Nanog associates with Drosha and an RNA helicase p68, which leads to oncogenic miRNA-21 transcription and a reduction in the expression of the tumor suppressor programmed cell death 4 (PCD4) (77). CD44v6-associated overexpression of miR-21 (78) induces pre-B-cell lymphoma (79), and is frequently observed in CML (80). Analyzing the impact of CD44v6 on the miRNA profile in metastasizing CIC (81) revealed CD44v6-dependent downregulation of the tumor suppressors let-7b, let-7d, let-7e, miR101, and miR-34a. The latter, which suppresses tumor growth by CD44 downregulation (82), is abundantly expressed in CD44v6 knockdown (CD44v6 ${ }^{\mathrm{kd}}$ ) cells, which argues for CD44v6 to be engaged in miR-34a silencing. On the other hand, metastasispromoting miR-494 and miR-21 and apoptosis-regulating miR24-1 (83-85) are abundant only in CD44v6-competent cells. miRNA transcription and/or posttranscriptional regulation also were affected by CD44v6-associated MET (86), which supports miR-103 transcription (87). MiR-103 expression was only high in CD44v6-competent cells.

We are also far away from a comprehensive view on the regulation of CD44 via miRNA. MiR-199a binding to the CD44 3'-UTR suppresses tumorigenicity, multidrug resistance, and migration $(88,89)$. The CD44 $3^{\prime}$-UTR binds additional miRNA that target extracellular matrix (ECM) mRNA, like miR-328, miR-491, miR671, and miR-512-3p. In fact, transfection-induced CD44 $3^{\prime}$-UTR overexpression is accompanied by collagen I and $\mathrm{FN}$ upregulation (90). However, stressing the need for further studies, opposing findings have also been reported, such as downregulation of CD44 by pro-metastatic miR-373/520c (91).

Finally, aberrant and alternative splicing is frequently observed in CIC/LIC, and CD44 ranks first in the affected genes (92). However, no mutations were found in cis acting CD44 splice elements (93). Thus, a genetic basis for CD44 alternative splicing in malignancies remains questionable.

Taken together, though links between CD44 and master SC genes, dominating SC signaling pathways, and epigenetic regulation of SC genes were described, HSC do not essentially depend on CD44. This could have been expected, as HSC are not or not seriously affected in panCD $44^{\mathrm{ko}}(94), \mathrm{CD} 44 \mathrm{v} 10^{\mathrm{ko}}(95), \mathrm{CD} 44 \mathrm{v} 7^{\mathrm{ko}}$, or CD44v6/v7 ${ }^{\mathrm{ko}}$ (96-98) mice.

On the other hand, it is already known since 1990 that CD44 is required for the development and maintenance of early hematopoietic progenitors. In long-term bone marrow (BM) cultures, tightly packed clusters of small cells, so called cobble stone areas, develop below a stroma layer. These cobble stones contain cells with the capacity for long-term reconstitution. When cultures contain anti-CD44, HSC clusters do not develop (99). Furthermore, CD44 is a reliable LIC marker in many malignancies (100), 
and the first LIC biomarker that blockade severely affected LIC maintenance, e.g., anti-CD44 drives LIC into apoptosis $(101,102)$. Thus, the essential contribution of CD44 relies on the communication of SC/HSC and LIC with the surrounding. In the following sections, those features of HSC are discussed that depend on or are modulated by the surrounding. This includes the requirement for a niche to maintain quiescence and to receive signals that drive out of quiescence toward differentiation. The latter frequently is associated with changes in motility. Finally, HSC are relatively apoptosis resistant. It also will be discussed, where LIC, which resemble HSC in many respects, become less dependent on the surrounding or respond differently due to the oncogenic transformation.

\section{The Endosteal Niche}

The fate of a cell in the developing organism is determined by its position $(103,104)$. SC reside in specialized locations, the niches, which minutely regulate their activity (105). Niches are composed of epithelial and mesenchymal cells and extracellular substrates. They govern location, adhesiveness, retention, homing, mobilization, quiescence and activation, symmetric and asymmetric division, and differentiation (106). Accordingly, a niche might prevent tumorigenesis, which would argue against CIC/LIC profiting from a niche. However, there is ample evidence that a preformed niche supports CIC/LIC survival and homing (105) and regulates the balance between quiescence and growth (107). Beyond this, a niche can support reprogramming of non-CIC toward CIC by exposing them to an embryonic microenvironment (108). CD44 plays a central role in the crosstalk between SC/malignant SC and the niche, which includes an active contribution of CD44 in niche assembly.

\section{The Composition of HSC and LIC Niches}

A niche for HCS, where they receive instructions particularly in respect to their lifelong capacity for self-renewal, was first proposed by Schofield in 1978 (109). Only 25 years later, it was uncovered that osteoblasts lining the surface of the bone play a major role (110). Additional cellular components of the endosteal niche are mesenchymal stem cells (MSC), osteoclasts, M $\phi$, fibroblasts, and adipocytes $(111,112)$. Interestingly, MSC, too, are influenced by their surrounding. Thus, it was expected that MSC from different tissue fulfill equivalent biological activities. On the contrary, when implanting MSC from BM, white adipose tissue, umbilical cord or skin, only BM-derived MSC spontaneously formed a BM cavity, which was progressively replaced by hematopoietic tissue and bone and permitted homing and maintenance of long-term murine and human HSC (113). Matrix components of the endosteal niche are HA, FN, laminin, and collagen that are secreted by endosteal niche cells and support HSC adhesion, quiescence, and self-renewal. Prominent cytokines and chemokines secreted by BM stroma cells (BM-Str) and/or captured by the BM stroma are thrombopoetin (TPO), SDF1, OPN, and parathyroid hormone. TPO promotes HSC quiescence (114). SDF1 supports quiescence and affects apoptosis resistance (115). OPN is engaged in lodgment to the endosteum (116), and parathyroid hormone supports trabecular network formation of osteoblasts and HSC expansion (117).
Hematopoietic SC avail on a second niche, the vascular niche, which is located in proximity to endothelial cells (118). Though components and activities of the endosteal and the vascular niche are partly overlapping (119), distinct to the endosteal niche, the vascular niche plays a major role in HSC homing and hematopoietic progenitor egress. The vascular niche also supports hematopoietic progenitor expansion and maturation. In line with these special duties, reticular cells in the vascular niche express IL6, HGF, OPN, and SDF1 at high or higher levels than cells in the osteogenic niche (120).

Thus, possibly distinct to ASC in solid organs, HSC dispose of two niches. The requirement for two niches might be linked to the general feature of cells of the hematopoietic system that are not sessile and circulate through the body to fulfill upon request their tasks in loco, and thereafter patrol again through the organism. Noteworthy, HSC/LIC CD44 contributes to the establishment of both BM niches.

\section{CD44 Contributes to the Generation of the BM Niches \\ The Contribution of CD44 to Matrix Assembly}

Stem cells niches, including the osteogenic niche in the BM, are particularly rich in HA (121). HSC synthesize and express HA, and HA expression correlates with HSC adhesion to the endosteal niche (122). Similarly, CD44 contributes to building an HA coat on endothelial cells, which facilitates binding of mobilized HSC to endothelial cells as well as HSC homing $(123,124)$. Furthermore, perturbation in matrix components alters cell shape and intracellular tension, which results in shifts in signaling events that affect gene expression (125). This could be particularly important in the $\mathrm{BM}$ niche, where HA delivery by HSC/LIC can induce expression of HA in niche cells (126). Furthermore, CD44 is involved in matrix assembly (127) such that the HA-CD44 association modifies the matrix to support colonization (128).

In concern about $\mathrm{CD} 44 \mathrm{v}$, there is evidence for an engagement of CD44v6 in matrix assembly. A CD44v6 knockdown ( ${ }^{\mathrm{kd}}$ ) in a highly metastatic tumor line revealed a striking reduction in metastatic capacity, which was, at least, partly due to an altered tumor matrix (81). CD44v6 $6^{\mathrm{kd}}$ cells secrete a matrix not supporting adhesion of $\mathrm{CD} 44 \mathrm{v}^{\mathrm{wt}}$ or $\mathrm{CD} 44 \mathrm{v} 6^{\mathrm{kd}}$ cells, whereas both cells readily adhere to the $\mathrm{CD} 44 \mathrm{v}^{\mathrm{wt}}$-matrix. In fact, HA synthase 3 (HAS3) expression is strongly reduced in CD44v $6^{\mathrm{kd}}$ cells (86), where high HAS3 expression frequently correlates with aggressiveness of carcinoma and leukemia (129). On the opposite, the CD44v6 $6^{\mathrm{kd}}$ cells abundantly secrete hyaluronidase such that the matrix contains a lower amount of HA and exclusively low molecular weight HA (130), which significantly affects adhesion and the catcher activity of the matrix (Figure 1A).

Briefly, HSC CD44 contributes to the generation of HSC niches mostly via HA provision, where the composition of HA varies depending on the expression of CD44v isoforms. CD44/CD44v strengthens HAS3 expression and, by not yet defined mechanisms, prohibits hyaluronidase activity.

\section{CD44 Contributes to the Catcher Activity of the Niche Matrix}

CD44 is a transmembrane proteoglycan, which allows for the local concentration of glycosaminoglycan-associating proteins (131). 


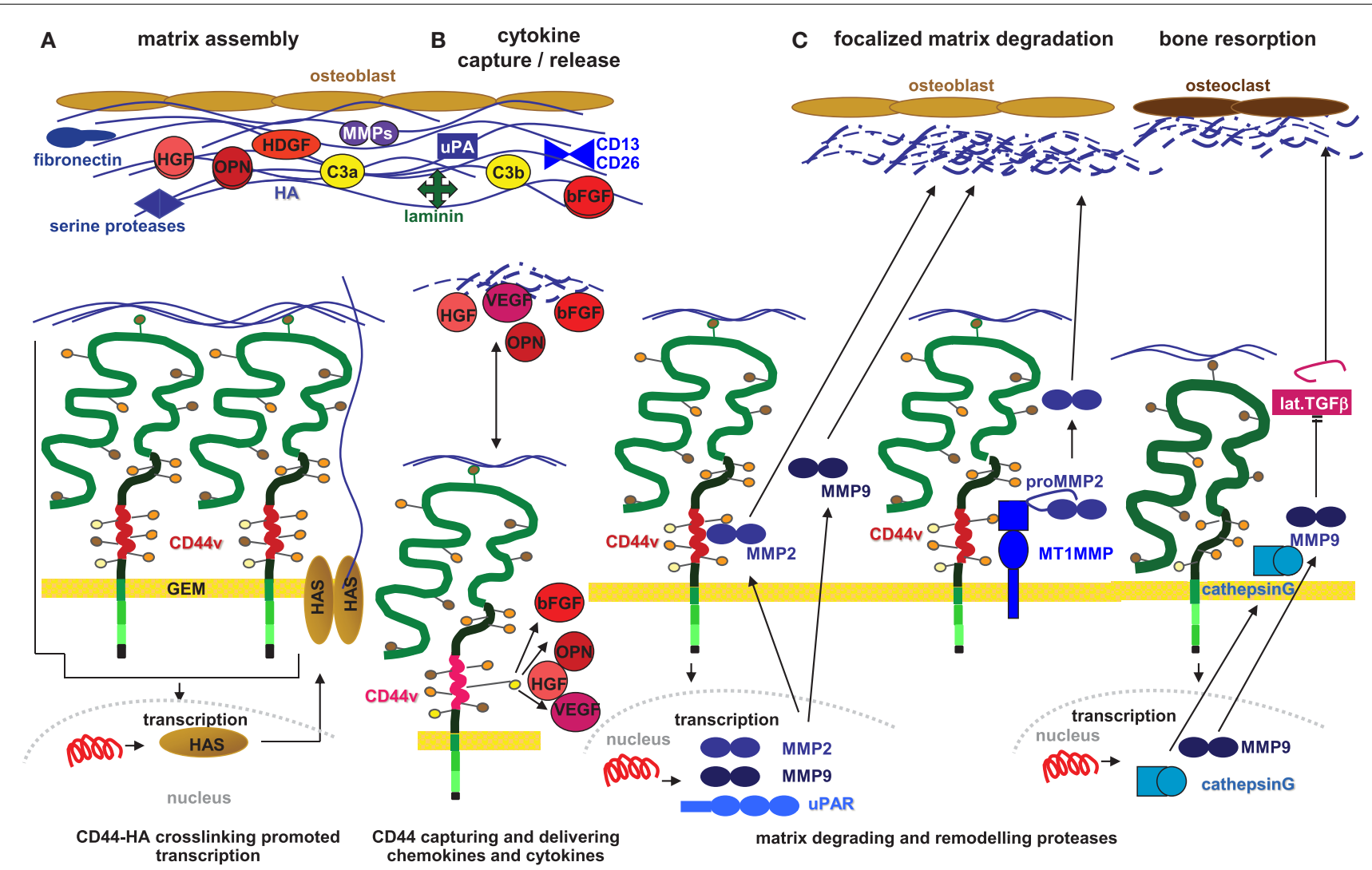

FIGURE 1 | The contribution of CD44 in HSC/LIC for assembly and modulation of the osteogenic niche. (A) HSC secrete large amounts of HA. Upon HA crosslinking, CD44 becomes activated, which supports transcription of HAS3, which strengthens the process of high MW HA deposition and incorporation of cytokines, chemokines, and proteases in the abundant $\mathrm{HA}$ coat. (B) HSC quiescence and LIC proliferation are supported by the catcher activity of CD44/CD44v6 and most pronounced CD44v3 associated GAG, which bind a large range of cytokines and chemokines including HGF, bFGF, OPN, and VEGF. (C) Particularly, LIC contribute to modulation of the matrix in the osteogenic niche. This is due to CD44-HA initiated transcription of MMP2, MMP9, UPAR, and cathepsinG. MMP2 and MMP9 bind to CD44; proMMP2 is cleaved by CD44v6-associated MT1MMP, which concomitantly allows for focal matrix degradation. CathepsinG and MMP9-activated TGF $\beta$ contributes to bone resorption and niche preparation for LIC.
Of special interest for HSC and LIC is the binding of OPN to CD44v3, CD44v6, and CD44v10 $(47,132,133)$, where OPN secretion is further stimulated by HA (134). OPN is chemotactic and haptotactic, and as such important for the recruitment of HSC into the niche (135). On the other hand, the OPN-CD44 interaction exerts a feedback on the donor cell, which supports migration. Thus, $\mathrm{p} 53^{\mathrm{ko}} \mathrm{CD} 44^{\mathrm{ko}}$ mice have the same rate of primary tumor development as $\mathrm{p} 53^{\mathrm{ko}}$ mice, but tumors do not metastasize (136). Similarly, a blockade of CD44v10 strongly reduced OPN delivery by leukemic cells, which was accompanied by pronounced retention of HSC in the niche (137). CD44v6 also binds VEGF and HGF $(44,45,138,139)$. In the hypoxic environment of the osteogenic niche, HIF1 $\alpha$ acts as a regulator to prevent HSC proliferation and exhaustion, where it is supported by VEGF, a target of HIF1 $\alpha$ (140). Instead, leukemic cells, which were supported by VEGF-activated endothelial cells in the vascular niche, gain in cytotoxic drug resistance (141). In concern about HGF, it is worthwhile noting that a subpopulation of HSC responds to HGF by migrating toward skeletal muscles (142). CD44v3 binds bFGF that stimulates proliferation of underlying mesenchymal cells in the developing limb and affects BM MSC $(143,144)$. This might be due to bFGF inducing changes in HAS and hyaluronidase isoform expression (145). A direct contribution of CD44v3bound bFGF to the activity of bone MSC remains to be explored (Figure 1B).

Finally, CD44v6 can directly contribute to the composition of the niche matrix (130). CD44v6 supports transcription of hepatoma-derived growth factor, which stimulates the growth of fibroblasts, endothelial cells, and vascular smooth muscle cells, and recruits MSC (146). CD44v6 also promotes clusterin secretion that influences chemokine secretion and initiates stromal changes affecting intercellular communications (147). In addition, the complement $(\mathrm{C})$ components $3 \mathrm{a}$ and $3 \mathrm{~b}$ are absent in a CD $44 \mathrm{v} 6^{\mathrm{kd}}$ matrix, but are abundantly delivered by CD $44 \mathrm{v} 6^{\mathrm{wt}}$ cells (86). These findings are well in line with the innate immune system, particularly $\mathrm{C} 3$, cooperating with CD44 in HSC to strengthen the HSC CD44 - niche interaction [review in Ref. (148)] (Figure 1A).

\section{CD44 Modulates HSC Niches}

CD44 concentrates MMPs at the cell surface, where the production of UPAR, MMP2, and MMP9 is concomitantly stimulated by 
the interaction between HA and CD44 $(86,149)$. MMP9 transcription is actively supported by the CD44 intracellular domain (ICD), which binds to a MMP9 promoter response element (150). By a not yet defined mechanism, CD44v6 also is involved in uPAR transcription (86). CD44 aggregation via HA binding facilitates MMP binding (150). Furthermore, proMMP2 becomes activated through CD44v-associated MMP14, which is located in the leading lamella. As cell-bound MMPs are protected from their inhibitors, this allows for focal degradation of the ECM to form space for invading LIC (151). LIC also stimulate osteoclasts to secrete cathepsinG and MMP9 to resorb bone to create a niche. CathepsinG, primarily secreted by osteoclasts (152), is another transcriptional target of HA-CD44 signaling (153). Transforming growth factor $\beta$ (TGF $\beta$ ) activation through CD44-associated MMP9 promotes angiogenesis, invasion (154), and enhances osteoclast activity and bone resorption (155) (Figure 1C).

Taken together, HSC require a niche and CD44 contributes to niche assembly. The most prominent CD44 contribution relies on the stimulation of HA provision via pronounced HAS activation. CD44 also supports retaining growth factors and chemokines that are supplied by the different niche elements. This facilitates message delivery from the niche toward the HSC/LIC. There is evidence for a contribution of CD44v particularly in cytokine/chemokine retention. It remains to be explored whether this provides a pronounced profit from the niche for CD44v expressing LIC. CD44 also contributes to modulating the niche by hyaluronidases and proteases that transcription is promoted by CD44 or that become activated via direct or indirect associations with CD44. There is no evidence that LIC contribute to establishing a niche. Rather, LIC are suggested to make use of the HSC niche. It is still disputed whether LIC displace HSC from their niche or actively remodel/destroy the niche (156), such that HSC die by neglect. High hyaluronidase secretion by CD44v6 ${ }^{+}$ LIC could favor the latter.

\section{CD44 Supports Adhesion, Homing, and Migration of HSC and LIC CD44, HSC, and LIC Adhesion to the Bone Marrow Stroma}

One of the prime functions of the osteogenic niche is the retention of HSC to instruct for longevity and quiescence, which requires firm HSC adhesion. This task is mainly taken over by HA (157). $\mathrm{HA}$ binding initiates or, at least, influences most activities of CD44 (158). The importance of CD44 as an adhesion molecule for HSC and LIC has been amply demonstrated $(157,159)$. The particular engagement of the CD44-HA interaction was confirmed by the finding that HSC adhesion can be blocked by anti-CD44, soluble HA, or hyaluronidase (160).

CD44 adhesion to its ligand(s) induces up-regulation of additional adhesion molecules, mostly integrins, which strengthen HSC adhesion (161). This was intensely explored for the association of CD44 with $\alpha 4 \beta 1(162,163)$. Upon activation by HA adhesion, the two molecules directly associate (164), which is accompanied by $\alpha 4 \beta 1$-promoted stronger adhesion to $\mathrm{FN}$ and laminin (165). HSC $\alpha 4 \beta 1$ additionally supports the direct contact with stroma cells via ICAM1 binding (166). In line with the contribution of CD44 and $\alpha 4 \beta 1$ to the adhesion of HSC to the osteogenic niche, anti-CD44 and anti- $\alpha 4 \beta 1$ dislodge HSC from the BM niche $(167,168)$ (Figure 2A).

CD44 also participates in LIC embedding into the endosteal niche, such that targeting CD44 is considered a new strategy to eliminate persistent and drug-resistant LIC. In AML, CD44 is required for the transport of LIC to the HSC niche, and anti-CD44 antibodies alter the fate of the LIC by inducing differentiation (101). In a mouse model of CML, BCR-ABL1-transduced progenitors from CD44-mutant donors were defective in BM homing, which resulted in decreased engraftment and impaired CMLlike disease induction (100). These studies provided additional evidence that LIC may be more dependent on CD44 for settlement in the osteogenic niche than HSC (101). Studies in a murine model confirmed leukemia cell homing and growth retardation by a CD44-specific antibody (169). However, during reconstitution, a panCD44-specific antibody more efficiently interfered with HSC than leukemia cell settlement in the BM niche (82).

The latter topic, how to avoid replacement of HSC when attacking LIC, was recently approached in an elegant study aiming to find selective ligands for LIC in CML and AML. Alteration of the niche by osteoblastic cell-specific activation of the parathyroid hormone receptor attenuates BCR-ABL1 oncogene-induced CML-like myeloproliferative neoplasia, but enhances MLL-AF9 oncogene-induced AML, possibly through opposing effects of increased TGF- $\beta 1$ on the respective LIC. These results, though providing a first and very important hint toward sparing niche embedded HSC, also demonstrate that niches differ for distinct LIC (170). The use of CD44v specific antibodies could be an alternative for blocking LIC, but sparing HSC embedding in the niche. Unfortunately, our data so far point toward a dominating role of CD44s in niche embedding. Thus, adhesion of CD44v6/v $7^{\mathrm{ko}}$ and of CD44v7 $7^{\mathrm{ko}}$ HSC to BM-Str is unimpaired $(97,171)$.

Facing competition for the niche, it should be remembered that LIC might remodel the niche such that it no longer serves the requirements of HSC (172). This possibility did not yet receive appropriate attention. Nonetheless, growing awareness and elaboration of the differentiation potential of distinct SC populations, particularly of BM derived MSC, might finally allow reconstituting/replacing a niche, which was distorted by LIC.

Distinct to the contribution of HSC/LIC CD44 on adhesion, little is known on the engagement of stroma cell provided CD44. Anti-CD44v6 strikingly hampered stroma formation in rat longterm BM cultures, but had no impact on HSC embedding in a preformed stroma (173). In addition, recovery of HSC from wt mice in the BM of CD44v7 $7^{\mathrm{ko}}$ mice is severely impaired (97). In vitro studies confirmed that HSC poorly adhere to long term CD44v6/v7 $7^{\mathrm{ko}}$ and CD44v7 $7^{\mathrm{ko}}$ BM-Str $(171,174)$. Thus, BM-Str CD44 should not be neglected as it contributes to matrix assembly. A comprehensive evaluation is missing. However, the availability of conditional ko mice will facilitate answering the question.

There is overwhelming evidence confirming the important finding of Miyake that HSC require CD44 for embedding in the BM niche, and that dislodgement by anti-CD44 severely affects hematopoiesis. In view of the essential role of CD44 to anchor HSC in the osteogenic niche, care should be taken on the therapeutic use of anti-CD44 to drive LIC out of the niche. Despite promising results, further refinement is required to guarantee 


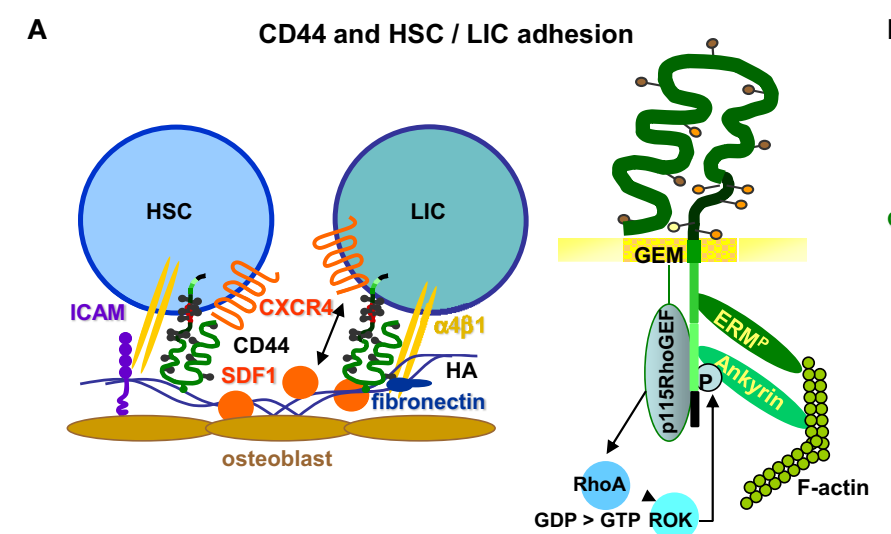

C CD44 and transferred HSC extravasation
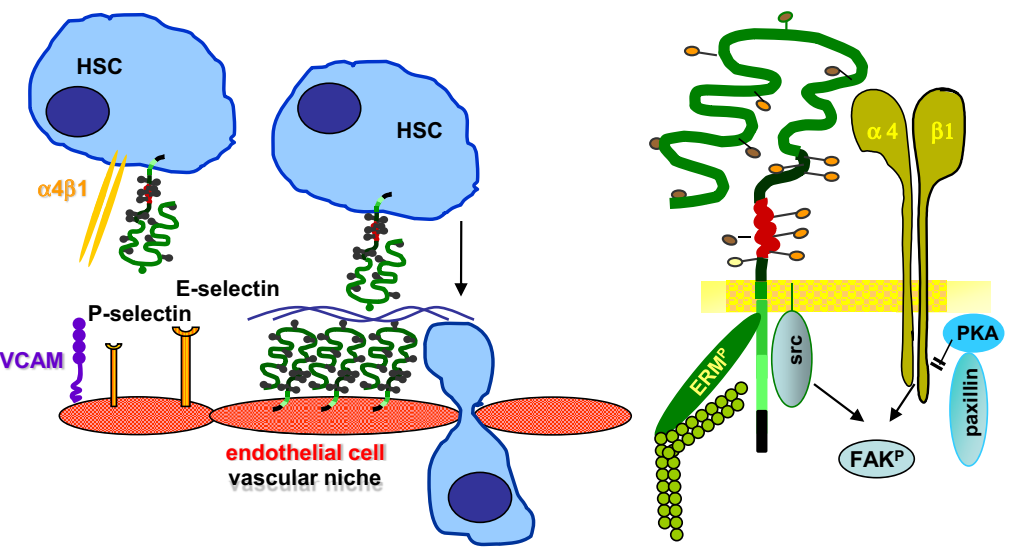

B

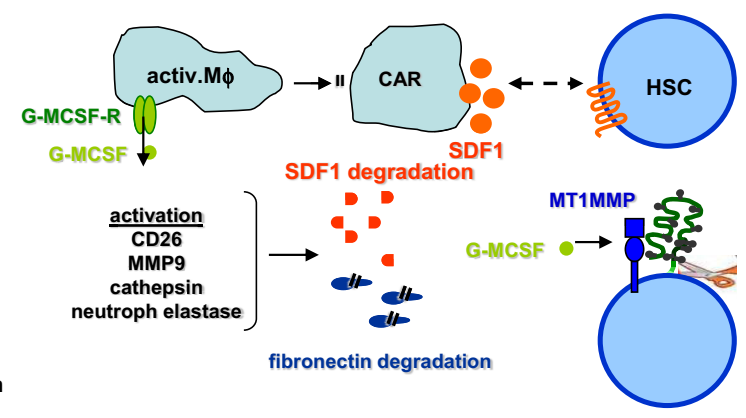

D CD44 and transferred HSC homing

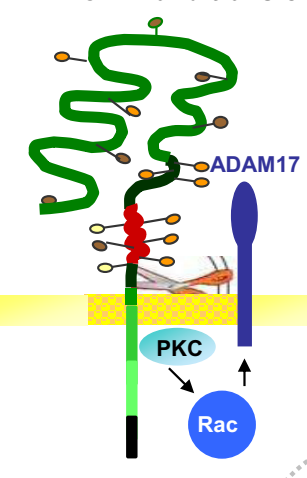

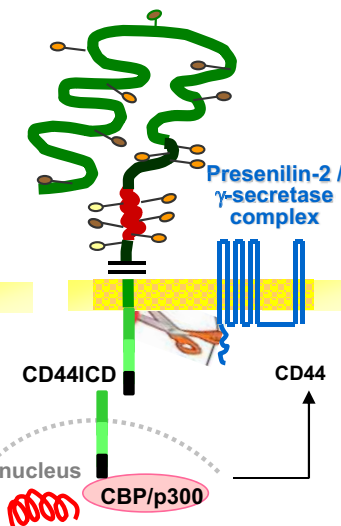

FIGURE 2 | CD44-mediated adhesion, mobilization, migration, and homing in HSC/LIC. (A) HSC and LIC adhesion to the HA-rich endosteal niche is supported by $\alpha 4 \beta 1$, which binds to fibronectin and via ICAM to osteoblasts. CD44-associated CXCR4 binding to stroma-derived SDF1 is of major importance in retaining HSC in the osteogenic niche. One of the adhesion strengthening signaling pathways proceeds via the CD44-crosslinking initiated activation of ERM and ankyrin, which includes activation of a RhoGEF that interacts with RhoA and stimulates ROK. This strengthens ankyrin phosphorylation and the F-actin linkage. (B) To interfere with the retention of HSC in the osteogenic niche for PBL-HSC transplantation, adhesion requires to be loosened. This is achieved by blocking CD44 and/or $\alpha 4 \beta 1$, and most commonly by G-MCSF that binds to $\mathrm{BM}-\mathrm{M} \phi$, which leads to activation of several proteases that degrade SDF1 and fibronectin. In addition, CAR become attacked and secrete less SDF1. Finally, G-MCSF leads to CD44-associated MT1MMP activation in HSC. By the CD44 cleavage, the adhesion of HSC becomes further reduced. (C) Homing of transferred HCS is facilitated by the constitutive expression of P-selectin and L-selectin on BM endothelial cells. CD44 binds to the selectins and $\alpha 4 \beta 1$ binds to VCAM-1, which supports loose attachment and rolling. CD44-promoted HA secretion further slows down HSC rolling and allows for extravasation. HA binding initiates activation of CD44, such that it binds to the cytoskeletal linker proteins ankyrin and/or ERM, which link CD44 to F-actin. CD44 moves from the trailing edge to the leading lamella such that the process of extravasation is initiated, where the activation-induced association with integrins plays an essential role. (D) It is discussed that the transient cleavage of CD44 by ADAM17 and liberation of the cytoplasmic tail (CD44ICD) by presenilin $2 / \gamma$-secretase facilitates departure from the endothelium of the $\mathrm{BM}$ vasculature. CD44ICD acts together with CBP/p300 as a transcription factor, besides others for CD44. Via this feedback, regain of CD44 allows for HSC adhesion in the osteogenic niche after arrival. unimpaired hematopoiesis. First trials to replace anti-CD44 have been successful, but point toward no single strategy being effective in distinct LIC. Additional studies are also needed to elaborate options for correcting niches, which were distorted by LIC.

\section{CD44 and HSC Mobilization}

Transplantation of hematopoietic progenitor cells provides in many instances an ultimate chance of curative leukemia therapy. It has become obvious that the transfer of peripheral blood HSC appears advantageous, yet it requires HSC mobilization. In 1976, Richman et al. described an increase of HSC in the blood of patients, who had undergone chemotherapy (175). Later, a similar increase was observed after the administration of recombinant growth factors (176). In fact, both G-CSF and chemotherapy mobilize HSC through the same mechanisms, with chemotherapy increasing the level of endogenous G-CSF (177). Though the precise mechanism remains to be elucidated, HSC mobilization obviously does not proceed directly, as HSC do not express the G-CSF receptor, which is expressed by BM macrophages $(\mathrm{M} \phi)$ (178). Activation of $\mathrm{M} \phi$ could result in a reduction of $\mathrm{Nes}^{+} \mathrm{MSC}$ and SDF1-abundant reticular cells (CAR), and their provision of SDF1 such that the SDF1-CXCR4 bond becomes loosened (179, 180). SDF1 is secreted by several BM-Str and its interaction with CXCR4 on HSC plays a key role in retention and trafficking. CXCR4 expression is enhanced through signaling cascades involving cAMP, PI3K, several GTPases, and PKC $\zeta$ (181). PKC $\zeta$ induces 
motility, adhesion and survival, and MMP2 and MMP9 secretion (182). Disruption of the SDF1-CXCR4 axis is the major mechanism leading to HSC release from their niche $(182,183)$. Alternatively, not mutually exclusive, upregulated expression of proteases may be involved, which can affect SDF1 (184) via MMP9 (185) or CD26 (186), cathepsin G and K, and neutrophil elastase (183). The same proteases also may account for VCAM1, FN, and OPN degradation (187). In addition, CD44 cleavage via MMP14 can contribute to HSC mobilization, where G-CSF leads to increased MMP14 expression in HSC $(188,189)$. Activation of the C cascade and plasminogen also contributes to HSC mobilization $(190,191)$ (Figure 2B).

Although G-CSF efficiently mobilizes HSC in most instances, some patients do not or insufficiently respond. In addition, GCSF treatment may by accompanied by maturation of the most primitive progenitors, and this impairs HSC homing and recovery of hematopoiesis. Therefore, additional approaches for HSC mobilization have been searched for, in particular, mobilization via a blockade of adhesion molecules expressed by CD34 ${ }^{+}$cells. As described above $(167,168)$, concomitant application of antiCD44 and anti- $\alpha 4 \beta 1$ most efficiently mobilizes HSC. Notably, most of the mechanisms suggested accounting for G-CSF-induced HSC mobilization might become initiated directly via the CD44 blockade. First, as CD44 is associated with CXCR4, SDF1-CXCR4 binding becomes loosened by a CD44 blockade (192). Second, antibody crosslinking of CD44 contributes to the activation of MMP9 and MT1MMP, which both are associated with CD44 (193).

In brief, mobilization, though mostly approached via G-CSF, can be achieved by directly loosening adhesion of HSC to the niche via anti-CD44 and/or anti- $\alpha 4 \beta 1$.

\section{CD44 and HSC Homing}

With the therapeutic transfer of mobilized HSC, the question arose on their homing. Transferred HSC preferentially home into the BM, where they search for the osteogenic niche (194). Homing is facilitated by the unique feature of BM endothelium that constitutively expresses the endothelial P- and E-selectins and VCAM1 (195). Proinflammatory cytokines stimulate CD44 expression in endothelial cells and strengthen their binding to HA. This promotes the arrest of HSC, which bind via CD44 to HA captured by endothelial cells (196). HSC express P-selectin ligands and CD44 as well as VCAM1 receptors such as $\alpha 4 \beta 1$ (197-199). Function blocking antibodies and targeted deletions confirmed the contribution of these adhesion molecules to slowdown HSC, which allows for firm adhesion and extravasation (200, 201) (Figure 2C).

CD44 also is involved in the extravasation of the endothelial cell-attached HSC (202). CD44-HA binding initiates the interaction of the CD44 cytoplasmic tail with the actin cytoskeleton through ankyrin and ERM proteins (196, 203), guiding CD44 to the leading edge of migrating cells (204). Thus, cells expressing CD44 with a truncated cytoplasmic tail retain HA-binding capacity, but loose the capacity to migrate on HA (204). One of the central events in CD44-mediated cytoskeletal reorganization appears to be Racl activation. Lamellipodia formation on HAcoated plates can be inhibited by a CD44 blocking antibody, but also by transfection of a dominant-negative mutant form of Rac1 (205). Upstream regulators of Rac1 are Vav1 and Vav2, phosphotyrosine-dependent guanine exchange factors of Rho GTPases. Vav phosphorylation is mediated by src kinases (206). As GEM-located CD44 associates with src (207), cytoskeleton reorganization most likely is initiated via src activation. Another mediator of CD44 signaling is RhoA. The RhoA-specific p115RhoGEF interacts with CD44 and regulates HA-mediated CD44 signaling via the serine-threonine Rho-Kinase (ROK), a downstream target of RhoA. ROK phosphorylates CD44, which promotes enhanced ankyrin binding (208). Another pathway of CD44 promoted motility proceeds via the association with $\alpha 4 \beta 1$. By associating with $\alpha 4 \beta 1, \mathrm{CD} 44$ gains access to FAK (focal adhesion kinase) and $\alpha 4 \beta 1$ gains access to src kinases and ERM proteins, such that the integrin-paxillin association becomes weakened and the GEM-integrated CD44-ezrin-integrin-FAK complex moves toward the leading edge $(164,209)$.

Cell motility is additionally supported by CD44 cleavage via a disintegrin and metalloproteinase domain (ADAM) protein and MMP-14 (210). CD44 cleavage is stimulated by $\mathrm{Ca}^{++}$ influx, which triggers ADAM10 activation after proADAM10 dissociation from calmodulin. ADAM17, which colocalizes with CD44 at Rac-regulated membrane ruffling areas, becomes activated by $\mathrm{PKC}$ and $\mathrm{Rac}$ and contributes to $\mathrm{CD} 44 \mathrm{v}$ cleavage $(211,212)$. Thus, the rapid activation of membrane-integrated proteases by CD44-HA binding contributes to a shift toward motility by CD44 cleavage. CD44 cleavage is tightly regulated, in part, by the missing activation of CD44-associated proteases after CD44 cleavage, and in part by cleavage-promoted CD44 transcription. After ectodomain cleavage, CD44 becomes accessible to the presenilin $/ \gamma$-secretase complex, which triggers intramembrane CD44 cleavage, setting free the CD44 ICD (CD44-ICD). CD44-ICD acts as a cotranscription factor that potentiates CD44 (28), MMP9, and MMP3 transcription (150)(Figure 2D).

As leukemia therapy frequently relies on autologous HSC transplantation, it became important to know whether LIC compete with HSC not only for the niche but also for homing. The described signaling pathways promoting HSC extravasation do not fundamentally differ for LIC. However, there are subtle differences. This was explored in an elegant study for BCR-ABL1-induced CML-like myeloproliferative neoplasia. Expression of $\alpha 4 \beta 1, \alpha 5 \beta 1, \mathrm{LFA} 1$, and CXCR4 did not differ between BCR-ABL1 $(+)$ progenitors and HSC, but expression of $\mathrm{P}$-selectin glycoprotein ligand-1 and of L-selectin was lower than in HSC. Deficiency of E-selectin in the recipient BM endothelium significantly reduced engraftment by BCR-ABL1-expressing SC. Destruction of selectin ligands on leukemic progenitors by neuraminidase reduced engraftment. BCR-ABL1-expressing Lselectin-deficient progenitors were also defective in homing and engraftment, and an L-selectin-specific antibody decreased the engraftment of BCR-ABL1-transduced SC. These results establish that BCR-ABL1(+) LIC rely to a greater extent on selectins and their ligands for homing and engraftment than HSC. Thus, a selectin blockade may be beneficial in autologous HSC transplantation for CML and perhaps other leukemia (213). 
After extravasation, transplanted HSC should reach the osteogenic niche. As mentioned, HSC synthesize HA (214), and HA expression supports HSC migration toward the endosteal niche (189). In the endosteal niche, SDF1 promotes adhesion through CD44-associated CXCR4 accompanied by rac1 and cdc42 activation $(182,192,215)$. These findings confirm the key role of HA and CD44 in SDF1-dependent HSC anchorage within specific niches (189). Finally, space is created by activated ROK, which phosphorylates the Na-H-exchanger1. Hyaluronidase-2 and cathepsinB become activated in the acidic milieu and support ECM degradation $(206,207)$.

Unfortunately, AML share the homing mechanisms with HSC $(216,217)$. However, the problem can possibly be circumvented in leukemia highly expressing CD44v6, as CD44v6 expression is low in HSC and HSC homing is dominated by CD44s. Analyzing migration of HSC from $\mathrm{CD} 44 \mathrm{v} 6 / \mathrm{v} 7^{\mathrm{ko}}$ and $\mathrm{CD} 44 \mathrm{v} 7^{\mathrm{ko}}$ mice toward HA and BM-Str revealed impaired migration toward FN, possibly due to CD44v6 directly binding to FN (218) or being promoted by the CD44v6- $\alpha 4 \beta 1$ association (174). Furthermore, HSC migration toward IL6 is strikingly impaired by anti-CD44v6 (219). Migration of CD44v7 $7^{\mathrm{ko}}$ and CD44v6/v7 ${ }^{\mathrm{ko}}$ HSC toward SDF1 was reduced to background levels, which indicates major importance of these two splice variants in migration along a SDF1 gradient (220). Binding and migration toward OPN is also impaired in $\mathrm{CD} 44 \mathrm{v} 6 / \mathrm{v} 7^{\mathrm{ko}}$ HSC. The finding fits the selective CD44v6 binding of OPN, which triggers migration and invasion (221, 222). Finally, BM-Str CD44v7 supports HSC migration (97). Thus, CD44v6/v7 are engaged in HSC migration toward chemokines/cytokines and BM-Str. Another protein selectively trapped by CD44v6 is C3 $(81,130)$. As elegantly elaborated by the group of Ratajczak [review in Ref. (223)], C3 can drive CXCR4 into lipid rafts, where it associates with CD44v6. Thereby, the CXCR4-SDF1 axis becomes strengthened, which helps retaining HSC in the niche. In a similar attempt elaborating homing of multiple myeloma to the BM, the authors explored differences in a stroma-dependent and a stroma-independent line. Only the stroma-dependent line expressed IGF-1R and CD44v6, where IGF-1 promoted chemotaxis toward BM-Str and CD44v6 supported adhesion. By modulating the culture conditions, the authors demonstrated that BM-Str promotes up-regulation of IGF-1R and CD44v6 in multiple myeloma, which facilitate homing and support adhesion to BM-Str (224).

Thus, the particular BM endothelium supports the egress of transplanted HSC into the BM. The engagement of CD44 relies on the provision of $\mathrm{HA}$ and the binding of CD44 to L-selectin, binding being supported by the association with integrins. Once attached to the endothelium, CD44 promotes activation of rac and rho, which initiate the shift toward a migratory phenotype. Migration is strengthened by activation of CD44-associated proteases. The proteases create space and cleave adhesion molecules including CD44, which fosters migration toward the endosteal niche. Settlement in the niche follows the path that underlies the preferential retention of HSC in the osteogenic niche. In most instances, LIC and HSC use the same adhesion molecules and signaling pathways for migration. Nevertheless and notably, there are some discrete differences between HSC and LIC, which may help elaborating protocols for preferential homing of transplanted HSC.

\section{CD44 and the Crosstalk Between HSC and the Niche}

CD44 does not only contribute to niche assembly but, importantly, there is a feedback from the niche toward HSC and LIC, which also involves CD44. Two aspects of this crosstalk will be in focus, the engagement of CD44 in (i) HSC quiescence and (ii) stress resistance, which both are linked to the osteogenic niche. Different to the engagement of CD44 in HSC and LIC homing and migration, mostly HSC rely on CD44-promoted quiescence. Instead, both HSC and LIC profit from CD44 in apoptosis resistance. Though the CD44-mediated crosstalk with the niche and the GEM location of CD44 are important for HSC and LIC apoptosis resistance $(225,226)$, the dominating mechanisms differ.

In advance of discussing the impact of the niche on CD44promoted quiescence and apoptosis resistance, exosomes need to be mentioned. Unfortunately, their impact on HSC and LIC has not yet been explored in detail. Many cells including HSC and LIC secrete small vesicles, called exosomes, which are supposed to be most efficient intercellular communicators (227-229), where miRNA transfer via exosomes can lead to target cell reprogramming (230). This was demonstrated for ESC exosomes reprogramming hematopoietic progenitors through miRNA delivery (231), and for the transfer of miRNA between different cells of the hematopoietic system as well as from CIC into BM-Str (232). Although the impact of CD44 on the exchange of exosomal miRNA between HSC/LIC and niche cells has not been elaborated, the impact of exosomal CD44v6 on miRNA transfer points toward the engagement of CD44 (78) and unquestionable demonstrated the strong impact of exosomal miRNA. Thus, a more comprehensive knowledge on the transfer of HCS exosomal miRNA should be approached, and can be expected to open new therapeutic options.

\section{CD44 and HSC Quiescence}

The quiescent state is critical for preserving self-renewal capacity and stress resistance of HSC. Besides intrinsic regulatory mechanisms, where p53 plays a dominant role, there are extrinsic microenvironmental regulatory mechanisms, which include angiopoetin-1, TGF $\beta$, bone morphogenetic proteins (BMP), TPO, $N$-cadherin, integrins, Wnt/ $\beta$-catenin, and OPN (233).

Angiopoietin is secreted by osteoblasts and binds to Tie 2 on HSC, which supports maintenance of quiescence and prevents cell division. Furthermore, the Tie2-angiopoietin interaction promotes cobblestone formation in long-term BM cultures (234). Besides strengthening adhesion of HSC to BM-Str (234), possibly via CD44, I am not aware of a particular linkage between the angiopoietin-Tie 2 axis and CD44 signaling.

TGF $\beta$ are potent inhibitors of HSC proliferation. TGF $\beta$ disruption increases circulating progenitor cells, and a bolus injection of TFG $\beta 1$ inhibited early progenitor proliferation. TGF $\beta$ mediated quiescence of HSC may be due to alteration in cytokine receptor expression and upregulation of cyclin-dependent kinase inhibitors (235). The engagement of CD44 relies on its interaction with the TGF $\beta$ R1 (236). TGF $\beta$ cooperates with HA-activated CD44 to induce expression of the NADPH oxidase (237), which could help regulating redox signals in HSC. 
Bone morphogenetic proteins, secreted by osteoblasts (238), potently inhibit HSC proliferation. BMP bind to their serine threonine kinase receptors on HSC, which leads to transphosphorylation and kinase domain activation, initiating phosphorylation of Smad 1, 5, and 8 that concomitantly associate with Smad4 and translocate to the nucleus. In the nucleus, they act as cotranscription factor regulating expression of target genes such as Runx1 and GATA2, which operate during specification of hematopoiesis (239) and regulate HSC quiescence (110, 240, 241). The linkage to CD44 is based on the association of CD44 with Smad1 (242). Alternatively, and BMP-independent, Smad1 can become phosphorylated via galectin- 9 , where galectin- 9 binding to CD44 promotes formation of a CD44/BMP receptor complex with concomitant BMP receptor activation (243).

Binding of TPO to its ligand (MPL) is critically involved in HSC steady-state maintenance with an over 150-fold reduction of HSC in $\mathrm{TPO}^{\mathrm{ko}}$ mice. Posttransplantation HSC expansion was highly MPL-and TPO-dependent. Accelerated HSC cell-cycle kinetic in $\mathrm{TPO}^{\mathrm{ko}}$ mice is accompanied by reduced cyclin-dependent kinase inhibitor $p 57^{K i p 2}$ and $p 19^{I N K 4 D}$ expression (244). The activity of TPO becomes strengthened by glucosaminoglycans in the matrix. Though this was demonstrated for megakaryocytopoiesis (245), it may have bearing on TPO affecting HSC embedded in the osteogenic niche.

Wnt signaling has emerged as an important factor in HSC quiescence, self-renewal, and differentiation (246). Wnt, secreted glycoproteins, binds to their sevenpass transmembrane receptors (Frizzled) (247) and low-density lipoprotein receptors LRP5 and LPR6 (248), which become phosphorylated and form an activated Frizzled/LPR receptor complex. The Frizzled/LPR receptor complex promotes dephosphorylation of $\beta$-catenin, which in the absence of Wnt signaling is phosphorylated and associated with a so-called destruction complex (249). Dephosphorylated $\beta$-catenin translocates to the nucleus, and together with LEF/TCF initiates transcription of Wnt target genes. In the noncanonical pathway, mostly Wnt5a signals via Frizzled using as coreceptor ROR, which leads to RhoA/Rac and JNK activation. In the Wnt-Ca ${ }^{++}$pathway, G-protein signaling is activated with upregulation of IP3-mediated release of intracellular $\mathrm{Ca}^{++}$and activation of PKC, which triggers nuclear translocation of NFAT and NFKB (246). Though Wnt is a potent morphogen (250), Wnt effects are highly context and dose-dependent (251), which makes it difficult to define precisely its role in HSC maintenance. To circumvent these difficulties, the group of Scadden used an osteoblast-specific promoter for expression of the Wnt paninhibitor Dickkopf1 (Dkk1). Binding to the coreceptor LRP5/6 leads to internalization of the complex (252). Inhibition of Wnt signaling in HSC resulted in reduced p21Cip1 expression, increased cell cycling, and a continuing decline in the reconstitution capacity of HCS. Notably, though the effect on HSC was microenvironmentdependent, HSC did not recover, when transferred in a normal host (253). Furthermore, Wnt-inhibition affected activation of the Notch target, Hes-1. This finding suggests that Notch and Wnt coordinately regulate HSC quiescence. Indeed, elevated Hes- 1 and p21 expression correlate with the maintenance of HSC quiescence (254). The importance of Notch signaling was confirmed by inhibition of Notch signaling diminishing the capacity of HSC to maintain an undifferentiated state. As proliferation and survival were not affected, the authors suggest that Notch "may act as a "gatekeeper" between self-renewal and commitment" (255).

Wnt signaling, in fact, is not only important for HSC [review in Ref. (62)], but the association of CD44 with Wnt signaling is also amply demonstrated for LIC [review in Ref. (61)]. However, as mentioned, Wnt effects are context dependent. Highlighting the differences to HSC, one example will be given. The cytoplasmic domain of GEM-located CD44 associates with the Wnt receptor LRP6, whereby LRP6 becomes recruited into the plasma membrane, which strengthens Wnt signaling and the accumulation of $\beta$-catenin in the nucleus, where down- and upregulation of CD44 directly affected Wnt signaling. Importantly, this activity of CD44 does not require CD44-HA crosslinking (256).

Osteopontin also negatively regulates the number of HSC in the $\mathrm{BM}$ niche. $\mathrm{OPN}^{\mathrm{ko}}$ mice display a significantly increased number of HSC, but not of committed progenitors (257). OPN also can modify primitive hematopoietic cell number and function in a stem cell-non-autonomous manner. This conclusion derived from the observation that the BM microenvironment of OPN ${ }^{\mathrm{ko}}$ mice was sufficient to increase the number of HSC, which was accompanied by an increase in stromal Jagged 1 and angiopoietin-1 expression and a reduction of primitive hematopoietic cell apoptosis (116). The authors discuss that the ECM plays a dynamic role in governing HSC responsiveness to expansion signals. Whether the signals are transferred via CD44-associated integrins (258) or directly via OPN binding to CD44 (133) remain to be explored. Instead, OPN binding to CD44v6 in CIC promotes activation of the PI3K/Akt pathway and promotes tumor growth (259). This is mentioned to remember that in concern of signal transduction, the peculiarities of HSC frequently do not allow a direct comparison to oncogene transformed CIC or LIC.

Finally, the interaction of SDF1, expressed by developing stroma in fetal bones, with HSC CXCR4 is critically for retaining HSC in the quiescence-protecting niche (260). Originally, it was noted that $\mathrm{SDF} 1^{\mathrm{ko}}$ and $\mathrm{CXCR} 4^{\mathrm{ko}}$ embryos have greater impairment of myelopoiesis in the BM than in the fetal liver, which suggested that SDF1 and CXCR4 are primarily involved in colonization of the BM by HSC during embryogenesis (261). Later on, elegant work with conditional CXCR $4^{\mathrm{ko}}$ mice implicated stromal SDF1 and its receptor in maintaining the pool of quiescent HSC. Conditional CXCR $4^{\mathrm{ko}}$ mice have a significantly increased pool of HSC in G1 compared to wt mice. This may be due to an altered environment with upregulation of cytokines, which promote HSC cycling and differentiation (115). Interestingly, actively signaling CXCR4 is associated with GEM localization (262). This implies that CXCR4 signaling sensitivity can be modulated by colocalization with other signaling molecules, including Rac1 (263). Notably, HA-crosslinked, GEM-located CD44 directly interacts with CXCR4, such that SDF1-CXCR4 signaling is abrogated in CD44 ${ }^{\mathrm{kd}}$ cells (264). Less is known about the impact of the niche on the resting versus cycling state of leukemia. However, it can be expected that due to oncogene transformation LIC are less susceptible to quiescence promoting signals from the niche or may even distinctly respond.

Figure 3 summarizes those signaling pathways in HSC, where CD44 is actively involved in maintaining HSC quiescence and 


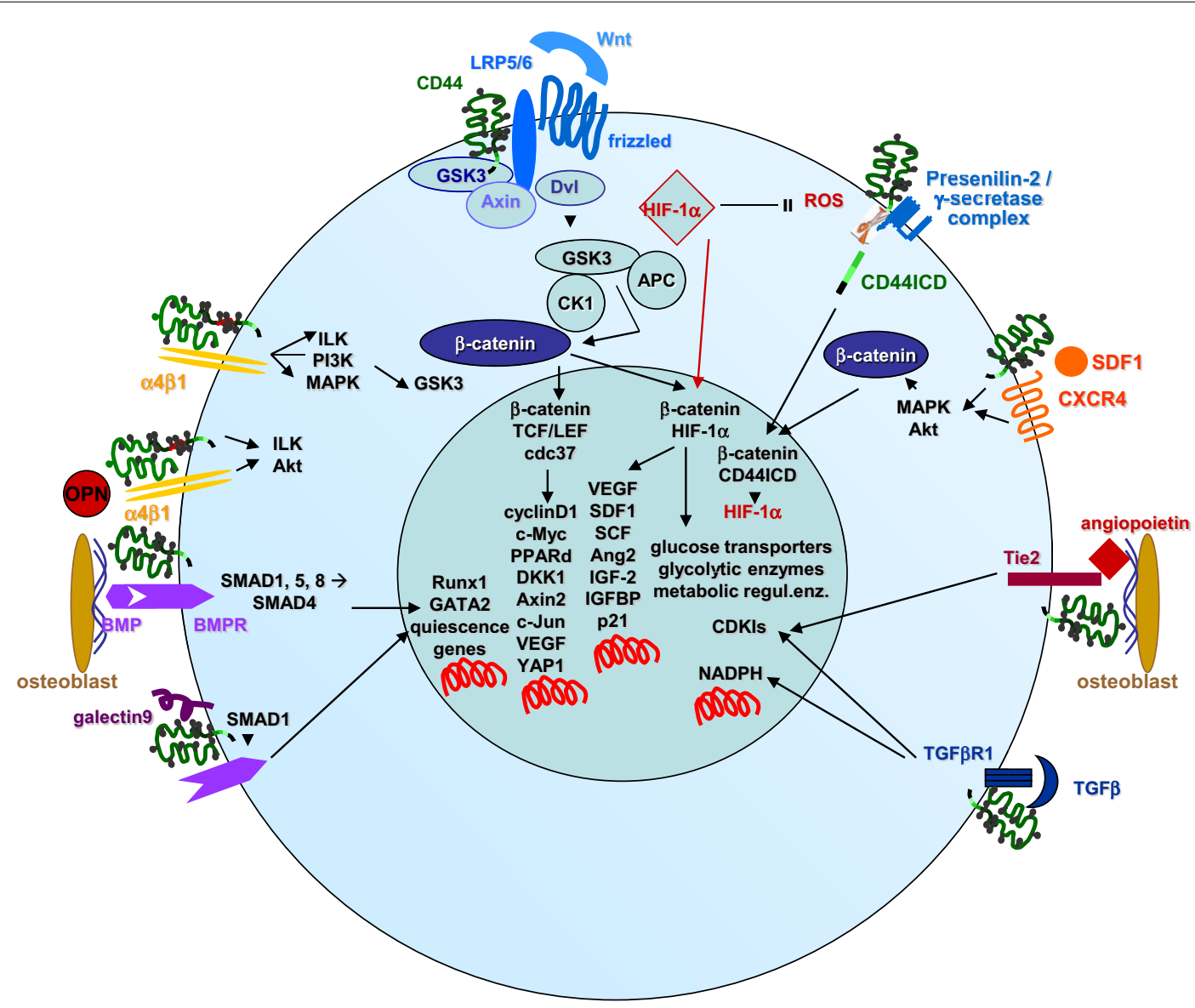

FIGURE 3 | CD44 imparts quiescence and oxidative stress protection in HSC. HSC quiescence and oxidative stress resistance are partly cell-autonomous processes, but are supported by a variety of interactions with BM-Str derived factors, where CD44 comes into play by its linkage and activation via $\mathrm{HA}$ binding as well as by its association with a variety of growth factor and chemokine receptors such as
LRP5/6, CXCR4, Tie2, the TGF $\beta R 1$, BMPRs, and $\alpha 4 \beta 1$. Only those signal transduction pathways and transcription factor activation/nuclear localization are shown, where HSC CD44 plays a major role. Notably, CD44ICD is suggested to be an important cotranscription factor for HIF-1a, the major regulator to cope with the low oxygen in the osteogenic niche.
HSC stress protection. Thus, CD44 becomes stimulated by several key molecules engaged in HSC quiescence. Alternatively, CD44, particularly when crosslinked by $\mathrm{HA}$, associates with quiescence regulating molecules.

Last, not least, the importance of the CD44-HA interaction was also demonstrated with $\mathrm{HAS}^{\mathrm{ko}}$ mice. HSC homing into the osteogenic niche depends on the HA coat of endothelial cells, and is significantly retarded in $\mathrm{HAS}^{\mathrm{ko}}$ mice (265). Furthermore, HA is required for the generation of HSC during differentiation of ESC (266). Finally, HSC seeded on HA rarely proliferate and retain multipotency $(267,268)$. All these findings strengthen the upmost importance of the CD44-HA crosstalk in HSC maintenance.

\section{CD44 and HSC Stress Resistance}

The distinction between HSC and LIC also accounts for a second phenomenon, the response to low oxygen pressure according to the location of HSC in niches (110), characterized by low oxygen concentration (269). Though LIC compete with HSC for the niche, they are not dependent on low oxygen and instead remodel the niche toward accumulation of inflammatory myelofibrotic cells, which drive LIC expansion, but compromise HSC maintenance (270). Notably, too, the metabolic status of HSC residing in a hypoxic BM environment also differs from that of their differentiated progeny (271).

Hematopoietic SC maintains redox homeostasis by low oxygen production due to the minimal metabolic rate $(271,272)$. Low metabolic rate maintenance further relies on asymmetric cell division, where the daughter cell, which remains in the SC state, inherits a very low level of energized mitochondria (273, 274). Furthermore, HSC generate energy mainly via anaerobic metabolism maintaining a high rate of glycolysis, which limits the production of reactive oxygen species. The hypoxia responsive regulatory pathways in HSC resembles that in other cells, HIF $1 \alpha$ being the master regulator driving the metabolic machinery toward anaerobic glycolysis (275). HIF1 $\alpha$, stabilized under hypoxic conditions (276), reprograms glucose metabolism via transcriptional activation of genes encoding glucose transporters, glycolytic enzymes, and metabolic regulatory enzymes, thereby switching from oxidative to glycolytic metabolism (277). One 
of the mechanisms proceeds via the HSP GRP78 and its ligand Cripto, HIF1 $\alpha$ binding to the Cripto promoter (278). The importance of HIF1 $\alpha$ orchestrating molecular responses, which maintain redox homeostasis in the face of changing $\mathrm{O}_{2}$ levels, was demonstrated by the loss of reconstitution capacity of HSC in HIF1 $\alpha^{\mathrm{ko}}$ mice (279). HSC dispose on additional regulatory molecules, including polycomb, DNA damage-related, and antioxidant proteins that participate in ROS regulation (280). Notably, maintenance of the hypoxic state of HSC is not restricted to the location in a poorly vascularized niche, but is dictated by cellspecific mechanisms derived from their glycolytic metabolic profile (281). Finally, the cotranscription factor CD44-ICD promotes expression of HIF2 $\alpha$ (282), as well as of additional hypoxiarelated genes, like aldolase c, 6-phosphofructose-2-kinase, pyruvate dehydrogenase kinase-1, and pyruvate dehydrogenase, which are directly associated with aerobic glycolysis (283-285). The authors point out that the repeatedly observed impact of the CD44-ICD on HIF expression in SC suggests a more active role of CD44-ICD in SC maintenance and protection as previously anticipated (282).

In concern about the engagement of CD44 and its ligands in protection from oxidative stress, it also was described that neural SC reside undifferentiated in a HA rich matrix, but proliferate and differentiate upon hyaluronidase upregulation (286). Additional contributions of CD44 and HA on stress protection may be shared by HSC and LIC and are described below.

Taken together, HSC circumvent stress, which would drive them into proliferation and exhaustion, mostly by a minimal metabolic rate and the generation of energy via anaerobic metabolism. The main contribution of $\mathrm{CD} 44$ relies on the cotranscription factor activity of CD44-ICD.

\section{CD44, LIC, and Apoptosis Resistance}

Besides contributing to circumvent stress, CD44 also actively promotes apoptosis resistance. From this activity of CD44, which does not appear to be of major importance for HSC stress resistance, LIC make profit. As to my knowledge, CD44-mediated apoptosis resistance proceeds in LIC and CIC via overlapping pathways, some examples of CIC will be included, where corresponding experiments have not yet been performed with LIC. There are two major mechanisms of CD44-mediated apoptosis protection: (i) initiation of signal transduction by CD44 crosslinking via HA, which frequently involves CD44v and associated RTK (287), and (ii) the crosstalk of CD44 with multidrug resistance genes that also is HA-dependent (288).

Apoptosis resistance initiated by the cooperation of CD44- or $\mathrm{CD} 44 \mathrm{v}$ with RTK mostly proceeds via activation of anti-apoptotic proteins. CD44 coimmunoprecipitates with all ERBB family members. The association of CD44 with ERBB2 and ERBB3 mediates heterodimerization and activation of the receptor in response to neuregulin, which strongly promotes CIC apoptosis resistance $(289,290)$. The impact of CD44 on ERBB2 activation is strikingly HA-dependent. CD44 crosslinking via HA initiates association of CD44 with ERBB2, which becomes phosphorylated. The complex, located in lipid rafts, includes ezrin, the chaperones HSP90 and CDC37, and PI3K, which accounts for drug resistance via activation of anti-apoptotic proteins. Apoptosis resistance is not seen when the HA-CD44 interaction is blocked, which causes complex disassembly and inactivation of ERBB2 (291). The authors also unraveled activation of an ERBB2-PI3K/Akt- $\beta$ catenin axis, which contributes to COX2 expression and COX2promoted suppression of caspase 3 activation. The data argue for a feedback loop, whereby COX2 strengthens HA production and promotes prostaglandin E2 expression (292). An additional feedback loop proceeds via formation of the ERBB2/ERBB4-CD44 complex, which via ERK activation promotes HA production by HAS1, -2, and -3 phosphorylation/activation (293) (Figure 4A).

Another, well-known pathway of apoptosis resistance involves the CD44v association with MET, which is initiated by HGF binding to CD44v3 or CD44v6 $(138,294)$, and promotes MET phosphorylation. MET phosphorylation requires the cytoplasmic tail of CD44 and the interaction with ERM proteins for activation of the Ras-MAPK pathway (294). CD44v6 binding to the ECM also activates the PI3K-Akt pathway and Wnt/ $\beta$-catenin signaling $(130,295)$ and regulates $M E T$ transcription $(86,296)$. Similar observations account for insulin-like growth factor-1 receptor and PDGFR activation through HA-stimulated CD44 in transformed cells $(133,297,298)$ (Figure 4A).

Importantly, CD44v6 promoted apoptosis resistance can also rely on the association of GEM-located CD44v6 with FAS. This association prevents trimerization of FAS upon ligand binding. Notably, apoptosis susceptibility strongly increases by a blockade of CD44v6 (299). Promoting FAS trimerization by a CD44v6 antibody blockade presents a new and interesting option in the therapy of CD44v6 expressing leukemia.

The interaction between CD44 and RTK can also proceed via proteases. CD44v3 binds the proform of the heparin binding epidermal growth factor (HB-EGF), which is cleaved by CD44recruited MMP7. Cleaved HB-EGF binds and activates ERBB4, which signals for cell survival $(300,301)$. The interaction of CD44 with MMP9 leads to apoptosis protection independent of RTK. CD44 and MMP9 expression are interdependent (149), and in CLL patients with poor prognosis CD44, CD49, and MMP9 are physically associated $(302,303)$. CD44-associated MMP14 accounts for proMMP9 cleavage (191). Activated MMP9 can interfere with TGF $\beta$ activation, whereby several mechanisms of TGF $\beta$-promoted apoptosis become silenced $(304,305)$.

An additional pathway of CD44-promoted resistance to reactive oxygen- and cytotoxic drug-induced stress under physiological and pathological conditions proceeds via the mammalian Hippo signaling pathway. In the resting state, CD44-associated merlin accounts for JNK, p53, and p21 upregulation, and YAP as well as ciAP1/2 downregulation, which jointly promote caspase 3 activation and apoptosis. When CD44 becomes activated by HA binding, merlin is phosphorylated and dissociates from CD44. In the absence of merlin, CD44 directly regulates YAP expression via active RhoA. Thereby, the HIPPO pathway becomes blocked, which results in increased apoptosis resistance (306, 307). In a feedback loop, activated YAP binds to the promoter of RHAMM, thereby inducing RHAMM transcription $(308,309)$ (Figure 4B).

Besides via CD44-associating molecules, the direct interaction between CD44 and HA strongly affects apoptosis resistance. Exploring the effect of HA on the extent of DNA damage induced 


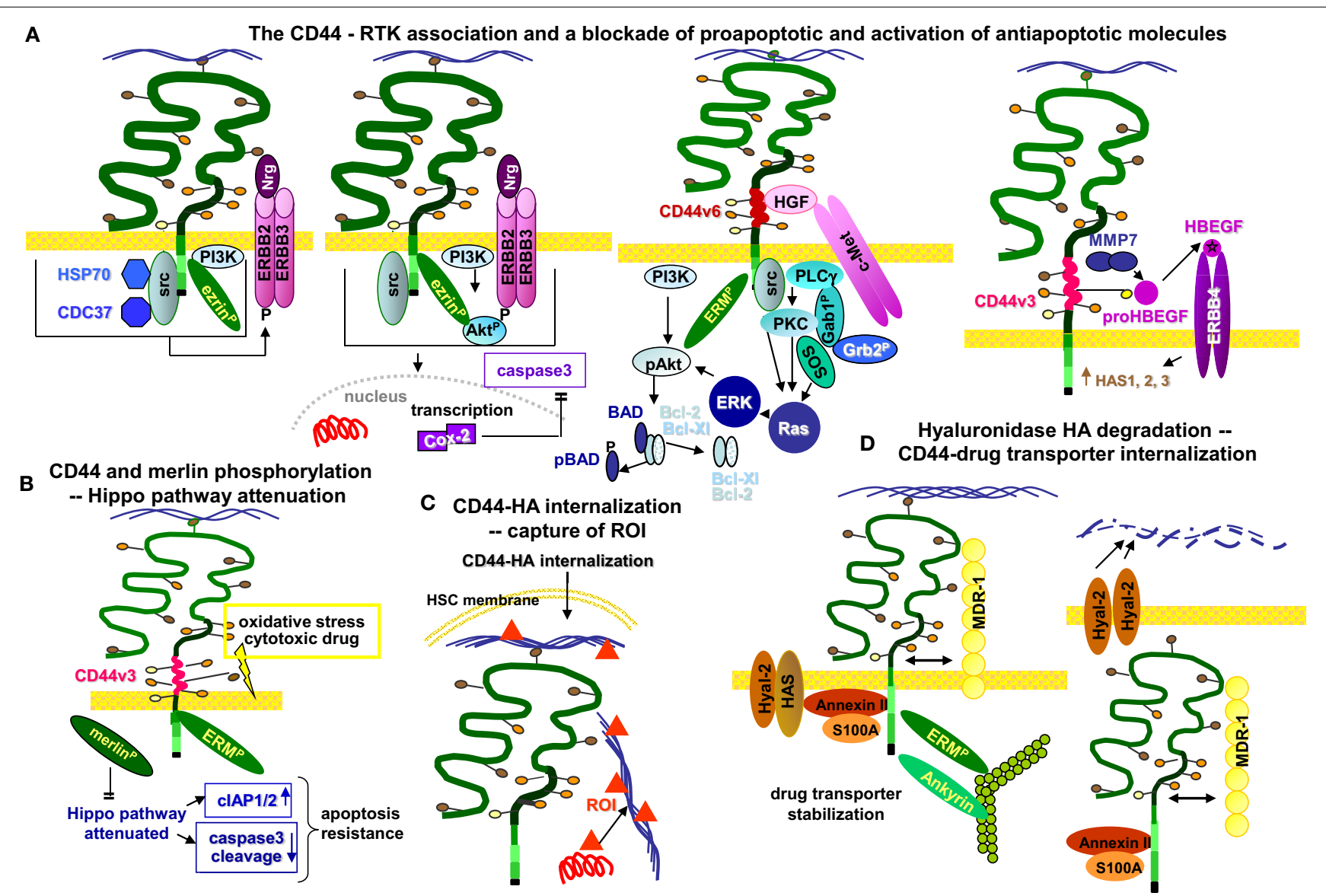

FIGURE 4 | CD44 interferes with apoptosis resistance in HSC/LIC.

(A) Four major pathways of RTK-promoted apoptosis protection are shown. (i) CD44-HA binding is accompanied by activation of CD44-associated src, ezrin phosphorylation, and PI3K activation, and assembly of a complex that includes, in addition, HSP70 and the co-chaperone CDC37, which promotes phosphorylation and activation of the ERBB2/ERBB3 RTK. (ii) The CD44-ERBB2/ERBB3 complex also provides a strong stimulus for Cox-2 transcription, which interferes with caspase 3 activation. (iii) CD44v6 binds HGF and presents it to MET. Activation of the latter and the downstream signaling cascades require concomitant activation of CD44 associated pERM and src. Importantly, joining of signaling via the Ras/MAPK and the PI3K/Akt pathway that rely on the CD44 cytoplasmic tail can be initiated without any additional stimuli by a CD44v6-assembled matrix. (iv) CD44v3 binds proHBEGF, which becomes cleaved via CD44-associated MMP7. HBEGF binds and activates ERBB4. All of these CD44-RTK associations strongly promote activation of signaling cascades that block apoptosis and upregulate anti-apoptotic proteins.
(B) Oxidative stress promotes merlin phosphorylation and dissociation from CD44. Merlin plays an important role in controlling the Hippo pathway. In CD44v expressing LIC, merlin is replaced by pERM, such that CIAP becomes increased and caspase3 activation does not take place, forcing LIC resistance toward cytotoxic drugs. (C) Particularly in HSC residing in the osteogenic niche, it has been observed that CD44-attached highMW HA can become internalized together with $\mathrm{CD} 44$, where $\mathrm{HA}$ acts as a catcher of $\mathrm{ROI}$, which protects DNA from damage. (D) MDR proteins are associated with activated CD44 (highMW HA-ligated and associated with pERM). Instead, lowMW HA promotes CD44 and concomitantly MDR internalization, which is accompanied by a significant increase in cytotoxic drug sensitivity. Maintenance of the complex between CD44, pERM, actin, and MDR-1, as well as the recovery of the S100A/Annexinll complex indicates internalization within caveolae and/or GEM. As far as LIC compete with HSC for the osteogenic niche, they will profit from the highMW HA matrix that via CD44 stabilizes MDR proteins within the cell membrane contributing to drug resistance. by exogenous and endogenous oxidants revealed that CD44 in SC internalizes HA by endocytosis. One of the functions of the internalized HA is the protection of DNA from oxidants. The authors propose entrapment of iron ions. Thereby the Fenton's reaction, which produces secondary oxidative species becomes inhibited. Alternatively, though not mutually exclusive, HA directly scavenges primary and secondary ROI, which results in intracellular HA degradation (310). Palmitoylation and GEM recruitment of CD44 is a precondition for HA internalization (311). Thus, attenuating oxidant-induced damage can proceed through direct scavenging of oxidant molecules by HA (312) (Figure 4C).
Drug resistance can also be promoted through CD44v3-HA binding, which via the Oct4-Sox2-Nanog complex induces miR302 transcription (74). The CD44-HA induced nuclear translocation of Nanog also leads to miR-21 production and upregulation of apoptosis inhibitors and MDR1 $(77,313)$.

Last, the interplay between CD44 and HA accounts for rapid drug elimination via drug transporters (288), which creates a major obstacle in leukemia and cancer therapy (314). Both CD44 and HA contribute to drug resistance. MDR genes are associated with CD44 and CD44 regulates expression of drug transporters. This likely is due to HA-activated CD44 binding to Gab1, which 
promotes PI3K activation. Activated PI3K stimulates HA production as well as MDR transporter expression $(315,316)$. Alternatively, though not mutually exclusive, HA binding to CD44 up-regulates p300 expression and its acetyltransferase activity. This, in turn, promotes acetylating $\beta$-catenin and NFKB-p65. Activated $\beta$-catenin and NFAT act as cotranscription factors with $\mathrm{NF \kappa B}$ in MDR1 transcription (317). The direct involvement of HA was demonstrated by replacing high MW by low MW HA. In the presence of high MW, HA activated CD44 is predominantly recovered in GEM and is associated with ERM and actin. MDR1 is associated with CD44 and the association stabilizes MDR1 expression. Instead, low MW HA does not stabilize the complex, but rather supports internalization such that all components of the complex including S100A and Annexin II are recovered in the cytoplasm (318). Whether the internalized complex becomes degraded or released as exosomes has not been explored. Independent of the answer to this question, the reduction of MDR1 in the cell membrane is accompanied by increased drug susceptibility (319). Notably, the three hyaluronan synthases are supposed to produce HA of different size. However, this as well as the major transcription factors engaged in HAS1, -2, and 3 transcription remain to be defined. Transcriptional regulation of hyaluronidases also awaits unraveling $(320,321)$. Taking into account that hyaluronidase as well as small HA oligosaccharides can improve drug efficacy (318), and that HA-CD44 cross-linking regulates expression of drug transporters $(315,316)$, filling this gap becomes demanding to improve therapeutic targeting of HA [review in Ref. (322, 323)] (Figure 4D).

The major importance of CD44 in apoptosis resistance relies (i) on the association of activated (HA-crosslinked) CD44/CD44v with RTK, which promote activation of anti-apoptotic signaling cascades, (ii) on interferences of CD44v6 with FAS trimerization, and (iii) the engagement of CD44 in regulating drug-resistance gene expression. The impact of CD44 is efficiently reinforced by high MW, but not low MW HA, where the latter may open a therapeutic window.

\section{Open Questions}

This review highlights the importance of CD44 in the crosstalk between HSC/LIC and the surrounding matrix. However, due to space constraints, this review does not cover the role of CD44 in all aspects of hematopoiesis and leukemia induction; this can be found within an excellent review which also focuses on signal transduction and transcription (324). Furthermore, while CD44based therapeutic concepts have been highlighted in individual sections within this review, there is some excellent literature which describes CD44 antibody and vaccination-based therapeutic concepts that may be of further interest to the reader (325-332). However, there are a number of key issues/questions that need to be addressed before a major therapeutic breakthrough can be achieved:

1. More information on the active contribution of the niche is required as well as the contribution of the individual components. This includes the possible transfer of information, comprising miRNA, via exosomes and accounts for HSC and LIC.
2. There is insufficient information on the modulation of the osteogenic niche by LIC, to safely protect HSC, if LIC was to be targeted, and to reconstruct a destroyed niche for unimpaired hematopoiesis.

3. The generation of LIC is not well understood. Again, the possibility has to be taken into account that LIC are instructed by surrounding cells, preferably HSC or MSC, via exosomes. Furthermore, there is a paucity of knowledge on the decision for self-renewal versus differentiation, which to some degree also accounts for HSC.

4. Much progress has been made in homing, migration, and signal transduction, which could well become the first question to be comprehensively answered.

In summary, the specific therapeutic targeting of LSC is still very much a field in its infancy (323). However, there is justified hope that this may change in the near future.

\section{Conclusion}

Stem cells require a niche, which has been particularly well explored for HSC, where the central importance of the CD44-HA interaction, including more recently the cellular stroma elements, is amply demonstrated. The CD44-HA crosstalk promotes adhesion and via cytokines/chemokines harbored in the BM-Str, homing, and migration of HSC as well as HSC quiescence and resistance to low oxygen pressure. LIC share with HSC the requirement for the crosstalk with the stroma to promote adhesion, homing, and migration. Apoptosis resistance of LIC, though strikingly dependent on the CD44-HA crosstalk, proceeds differently to that of HSC predominantly via CD44v and the cooperation with RTK, proteases, and drug transporters.

The abundant array of HA-bound CD44-initiated activities relies on the cooperation of CD44 with multiple membrane molecules including integrins, chemokine receptors, RTK, and proteases as well as its transient association with cytoskeletal linker molecules and cytoplasmic signal transducers, which includes central stem cell fate regulators. The multitude of interactions is fostered by the GEM location of CD44, which also promotes the proximity to proteases. Proteases facilitate CD44 cleavage, where the CD44-ICD acts as a cotranscription factor. It has been suggested, but needs further approval, that CD44-ICD also regulates miR transcription/repression of CD44 cooperation partners, thereby creating an additional feedback loop.

In view of the most promising results in leukemia therapy by blocking CD44, awareness increased on possible selective differences between HSC and LIC in the crosstalk with the osteogenic niche. Several elegant and sophisticated studies clearly demonstrated the existence of differences not only between HSC and LIC but also between distinct leukemia. Progress in this field will greatly facilitate selective therapeutic interference with LIC homing and may allow for corrections of the LIC-distorted osteogenic niche. The latter as well as the interaction with the vascular niche and homing into the osteogenic niche is of particular interest in view of the HSC transfer being frequently a last chance for curative therapy. Further clarifying HA production and degradation may also open new avenues for a therapeutic dissection between the HSC- and the LIC-HA crosstalk. Last, not least, uncovering the 
importance of miRNA and the role of exosomes in miRNA transfer will add optimizing the HSC-HA crosstalk in the osteogenic niche and will allow interfering with niche destructing activities of LIC.

\section{References}

1. Gallatin WM, Weissman IL, Butcher EC. A cell-surface molecule involved in organ-specific homing of lymphocytes. Nature (1983) 304:30-4. doi:10.1038/ 304030a0

2. Günthert U, Hofmann M, Rudy W, Reber S, Zöller M, Haussmann I, et al. A new variant of glycoprotein CD44 confers metastatic potential to rat carcinoma cells. Cell (1991) 65:13-24. doi:10.1016/0092-8674(91)90403-L

3. Naor D, Wallach-Dayan SB, Zahalka MA, Sionov RV. Involvement of CD44, a molecule with a thousand faces, in cancer dissemination. Semin Cancer Biol (2008) 18:260-7. doi:10.1016/j.semcancer.2008.03.015

4. Herrlich P, Zöller M, Pals ST, Ponta H. CD44 splice variants: metastases meet lymphocytes. Immunol Today (1993) 14:395-9. doi:10.1016/0167-5699(93) 90141-7

5. Ratajczak MZ. Cancer stem cells - normal stem cells "Jedi" that went over to the "dark side". Folia Histochem Cytobiol (2005) 43:175-81.

6. Zöller M. CD44: can a cancer-initiating cell profit from an abundantly expressed molecule? Nat Rev Cancer (2011) 11:254-67. doi:10.1038/nrc3023

7. Sales KM, Winslet MC, Seifalian AM. Stem cells and cancer: an overview. Stem Cell Rev (2007) 3:249-55. doi:10.1007/s12015-007-9002-0

8. Pei D. Regulation of pluripotency and reprogramming by transcription factors. J Biol Chem (2009) 284:3365-9. doi:10.1074/jbc.R800063200

9. Fábián A, Barok M, Vereb G, Szöllosi J. Die hard: are cancer stem cells the Bruce Willises of tumor biology? Cytometry A (2009) 75:67-74. doi:10.1002/ cyto.a. 20690

10. Adams JM, Strasser A. Is tumor growth sustained by rare cancer stem cells or dominant clones? Cancer Res (2008) 68:4018-21. doi:10.1158/0008-5472. CAN-07-6334

11. Conway AE, Lindgren A, Galic Z, Pyle AD, Wu H, Zack JA, et al. A pluripotency and self-renewal program controls the expansion of genetically unstable cancer stem cells in pluripotent stem cell-derived tumors. Stem Cells (2009) 27:18-28. doi:10.1634/stemcells.2008-0529

12. Wang JC. Good cells gone bad: the cellular origins of cancer. Trends Mol Med (2010) 16:145-51. doi:10.1016/j.molmed.2010.01.001

13. Alison MR, Guppy NJ, Lim SM, Nicholson LJ. Finding cancer stem cells: are aldehyde dehydrogenases fit for purpose? J Pathol (2010) 222:335-44. doi: $10.1002 /$ path. 2772

14. Screaton GR, Bell MV, Jackson DG, Cornelis FB, Gerth U, Bell JI. Genomic structure of DNA encoding the lymphocyte homing receptor CD44 reveals at least 12 alternatively spliced exons. Proc Natl Acad Sci US A (1992) 89:12160-4. doi:10.1073/pnas.89.24.12160

15. Stamenkovic I, Amiot M, Pesando JM, Seed B. A lymphocyte molecule implicated in lymph node homing is a member of the cartilage link protein family. Cell (1989) 56:1057-62. doi:10.1016/0092-8674(89)90638-7

16. Goldstein LA, Zhou DF, Picker LJ, Minty CN, Bargatze RF, Ding JF, et al. A human lymphocyte homing receptor, the hermes antigen, is related to cartilage proteoglycan core and link proteins. Cell (1989) 56:1063-72. doi:10.1016/ 0092-8674(89)90639-9

17. Idzerda RL, Carter WG, Nottenburg C, Wayner EA, Gallatin WM, St John T. Isolation and DNA sequence of a cDNA clone encoding a lymphocyte adhesion receptor for high endothelium. Proc Natl Acad Sci U S A (1989) 86:4659-63. doi:10.1073/pnas.86.12.4659

18. Goldstein LA, Butcher EC. Identification of mRNA that encodes an alternative form of H-CAM (CD44) in lymphoid and nonlymphoid tissues. Immunogenetics (1990) 32:389-97. doi:10.1007/BF00241632

19. Greenfield B, Wang WC, Marquardt H, Piepkorn M, Wolff EA, Aruffo A, et al. Characterization of the heparan sulfate and chondroitin sulfate assembly sites in CD44. J Biol Chem (1999) 274:2511-7. doi:10.1074/jbc.274.4.2511

20. Ishii S, Ford R, Thomas P, Nachman A, Steele G Jr, Jessup JM. CD44 participates in the adhesion of human colorectal carcinoma cells to laminin and type IV collagen. Surg Oncol (1993) 2:255-64. doi:10.1016/0960-7404(93)90015-Q

\section{Acknowledgments}

This work was supported by the Deutsche Krebshilfe (grant no. 109234 and 109144).

21. Jalkanen S, Jalkanen M. Lymphocyte CD44 binds the $\mathrm{COOH}$-terminal heparin-binding domain of fibronectin. J Cell Biol (1992) 116:817-25. doi:10. 1083/jcb.116.3.817

22. Konstantopoulos $\mathrm{K}$, Thomas $\mathrm{SN}$. Cancer cells in transit: the vascular interactions of tumor cells. Annu Rev Biomed Eng (2009) 11:177-202. doi:10.1146/ annurev-bioeng-061008- 124949

23. Aruffo A, Stamenkovic I, Melnick M, Underhill CB, Seed B. CD44 is the principal cell surface receptor for hyaluronate. Cell (1990) 61:1303-13. doi:10. 1016/0092-8674(90)90694-A

24. Peach RJ, Hollenbaugh D, Stamenkovic I, Aruffo A. Identification of hyaluronic acid binding sites in the extracellular domain of CD44. J Cell Biol (1993) 122:257-64. doi:10.1083/jcb.122.1.257

25. Lesley J, Hyman R, Kincade PW. CD44 and its interaction with extracellular matrix. Adv Immunol (1993) 54:271-335. doi:10.1016/S0065-2776(08) 60537-4

26. Toyama-Sorimachi N, Miyasaka M. A novel ligand for CD44 is sulfated proteoglycan. Int Immunol (1994) 6:655-60. doi:10.1093/intimm/6.4.655

27. Screaton GR, Bell MV, Bell JI, Jackson DG. The identification of a new alternative exon with highly restricted tissue expression in transcripts encoding the mouse Pgp-1 (CD44) homing receptor. Comparison of all 10 variable exons between mouse, human, and rat. J Biol Chem (1993) 268:12235-8.

28. Okamoto I, Kawano Y, Murakami D, Sasayama T, Araki N, Miki T, et al. Proteolytic release of CD44 intracellular domain and its role in the CD44 signaling pathway. J Cell Biol (2001) 155:755-62. doi:10.1083/jcb.200108159

29. Kalnina Z, Zayakin P, Silina K, Line A. Alterations of pre-mRNA splicing in cancer. Genes Chromosomes Cancer (2005) 42:342-57. doi:10.1002/gcc.20156

30. Liu D, Sy MS. Phorbol myristate acetate stimulates the dimerization of CD44 involving a cysteine in the transmembrane domain. J Immunol (1997) 159:2702-11.

31. Lokeshwar VB, Fregien N, Bourguignon LY. Ankyrin-binding domain of $\mathrm{CD} 44(\mathrm{Gp} 85)$ is required for the expression of hyaluronic acid-mediated adhesion function. J Cell Biol (1994) 126:1099-109. doi:10.1083/jcb.126.4.1099

32. Fehon RG, McClatchey AI, Bretscher A. Organizing the cell cortex: the role of ERM proteins. Nat Rev Mol Cell Biol (2010) 11:276-87. doi:10.1038/nrm2866

33. Mori T, Kitano K, Terawaki S, Maesaki R, Fukami Y, Hakoshima T. Structural basis for CD44 recognition by ERM proteins. J Biol Chem (2008) 283:29602-12. doi:10.1074/jbc.M803606200

34. Stamenkovic I, Yu Q. Merlin, a "magic" linker between extracellular cues and intracellular signaling pathways that regulate cell motility, proliferation, and survival. Curr Protein Pept Sci (2010) 11:471-84. doi:10.2174/ 138920310791824011

35. Oliferenko S, Paiha K, Harder T, Gerke V, Schwärzler C, Schwarz H, et al. Analysis of CD44-containing lipid rafts: recruitment of annexin II and stabilization by the actin cytoskeleton. J Cell Biol (1999) 146:843-54. doi:10.1083/ jcb.146.4.843

36. Neame SJ, Isacke CM. The cytoplasmic tail of CD44 is required for basolateral localization in ephitelial MDCK cells but does not mediate association with the detergent-insoluble cytoskeleton of fibroblasts. J Cell Biol (1993) 121:1299-310. doi:10.1083/jcb.121.6.1299

37. Zarbock A, Ley K, McEver RP, Hidalgo A. Leukocyte ligands for endothelial selectins: specialized glycoconjugates that mediate rolling and signaling under flow. Blood (2011) 118:6743-51. doi:10.1182/blood-2011-07-343566

38. Róg T, Vattulainen I. Cholesterol, sphingolipids, and glycolipids: what do we know about their role in raft-like membranes? Chem Phys Lipids (2014) 184C:82-104. doi:10.1016/j.chemphyslip.2014.10.004

39. Föger N, Marhaba R, Zöller M. Involvement of CD44 in cytoskeleton rearrangement and raft reorganization in T cells. J Cell Sci (2001) 114:1169-78.

40. Slotte JP. Biological functions of sphingomyelins. Prog Lipid Res (2013) 52:424-37. doi:10.1016/j.plipres.2013.05.001

41. Ruiz P, Schwärzler C, Günthert U. CD44 isoforms during differentiation and development. Bioessays (1995) 17:17-24. doi:10.1002/bies.950170106 
42. Zöller M. CD44: physiological expression of distinct isoforms as evidence for organ-specific metastasis formation. J Mol Med (1995) 73:425-38.

43. Bennett KL, Jackson DG, Simon JC, Tanczos E, Peach R, Modrell B, et al. CD44 isoforms containing exon $\mathrm{v} 3$ are responsible for the presentation of heparin-binding growth factor. J Cell Biol (1995) 128:687-98. doi:10.1083/jcb. 128.4.687

44. Orian-Rousseau V, Ponta H. Adhesion proteins meet receptors: a common theme? Adv Cancer Res (2008) 101:63-92. doi:10.1016/S0065-230X(08) 00404- 1

45. Tremmel M, Matzke A, Albrecht I, Laib AM, Olaku V, Ballmer-Hofer K, et al. A CD44v6 peptide reveals a role of CD44 in VEGFR-2 signaling and angiogenesis. Blood (2009) 114:5236-44. doi:10.1182/blood-2009-04-219204

46. Todaro M, Gaggianesi M, Catalano V, Benfante A, Iovino F, Biffoni M, et al. $\mathrm{CD} 44 \mathrm{v} 6$ is a marker of constitutive and reprogrammed cancer stem cells driving colon cancer metastasis. Cell Stem Cell (2014) 14:342-56. doi:10.1016/ j.stem.2014.01.009

47. Megaptche AP, Erb U, Büchler MW, Zöller M. CD44v10, osteopontin and lymphoma growth retardation by a CD44v10-specific antibody. Immunol Cell Biol (2014) 92:709-20. doi:10.1038/icb.2014.47

48. Williams K, Motiani K, Giridhar PV, Kasper S. CD44 integrates signaling in normal stem cell, cancer stem cell and (pre)metastatic niches. Exp Biol Med (2013) 238:324-38. doi:10.1177/1535370213480714

49. Zou GM. Cancer stem cells in leukemia, recent advances. J Cell Physiol (2007) 213:440-4. doi:10.1002/jcp. 21140

50. Nagano O, Okazaki S, Saya H. Redox regulation in stem-like cancer cells by CD44 variant isoforms. Oncogene (2013) 32:5191-8. doi:10.1038/onc. 2012.638

51. Tárnok A, Ulrich H, Bocsi J. Phenotypes of stem cells from diverse origin. Cytometry A (2010) 77:6-10. doi:10.1002/cyto.a.20844

52. Suzuki HI, Yamagata K, Sugimoto K, Iwamoto T, Kato S, Miyazono K. Modulation of microRNA processing by p53. Nature (2009) 460:529-33. doi:10.1038/ nature 08199

53. Gupta RA, Shah N, Wang KC, Kim J, Horlings HM, Wong DJ, et al. Long non-coding RNA HOTAIR reprograms chromatin state to promote cancer metastasis. Nature (2010) 464:1071-6. doi:10.1038/nature08975

54. Messaoudi-Aubert SE, Nicholls J, Maertens GN, Brookes S, Bernstein E, Peters G. Role for the MOV10 RNA helicase in polycomb-mediated repression of the INK4a tumor suppressor. Nat Struct Mol Biol (2010) 17:862-8. doi:10.1038/ nsmb. 1824

55. Kuçi S, Kuçi Z, Latifi-Pupovci H, Niethammer D, Handgretinger R, Schumm $\mathrm{M}$, et al. Adult stem cells as an alternative source of multipotential (pluripotential) cells in regenerative medicine. Curr Stem Cell Res Ther (2009) 4:107-17. doi:10.2174/157488809788167427

56. Kashyap V, Rezende NC, Scotland KB, Shaffer SM, Persson JL, Gudas LJ, et al. Regulation of stem cell pluripotency and differentiation involves a mutual regulatory circuit of the NANOG, OCT4, and SOX2 pluripotency transcription factors with polycomb repressive complexes and stem cell microRNAs. Stem Cells Dev (2009) 18:1093-108. doi:10.1089/scd.2009.0113

57. Cerdan C, Bhatia M. Novel roles for Notch, Wnt and Hedgehog in hematopoesis derived from human pluripotent stem cells. Int J Dev Biol (2010) 54:955-63. doi:10.1387/ijdb.103067cc

58. Lessard J, Sauvageau G. Bmi-1 determines the proliferative capacity of normal and leukaemic stem cells. Nature (2003) 423:255-60. doi:10.1038/nature01572

59. Sancho-Martinez I, Baek SH, Izpisua Belmonte JC. Lineage conversion methodologies meet the reprogramming toolbox. Nat Cell Biol (2012) 14:892-9. doi:10.1038/ncb2567

60. Hoffman B, Amanullah A, Shafarenko M, Liebermann DA. The protooncogene c-myc in hematopoietic development and leukemogenesis. Oncogene (2002) 21:3414-21. doi:10.1038/sj.onc. 1205400

61. McCubrey JA, Steelman LS, Bertrand FE, Davis NM, Abrams SL, Montalto G, et al. Multifaceted roles of GSK-3 and Wnt/ $\beta$-catenin in hematopoiesis and leukemogenesis: opportunities for therapeutic intervention. Leukemia (2014) 28:15-33. doi:10.1038/leu.2013.184

62. Katoh M. WNT signaling in stem cell biology and regenerative medicine. Curr Drug Targets (2008) 9:565-70. doi:10.2174/138945008784911750

63. Siapati EK, Papadaki M, Kozaou Z, Rouka E, Michali E, Savvidou I, et al. Proliferation and bone marrow engraftment of AML blasts is dependent on $\beta$ catenin signalling. Br J Haematol (2011) 152:164-74. doi:10.1111/j.1365-2141. 2010.08471.x
64. Nagase H, Koh CS, Nakayama K. $\gamma$-Secretase-regulated signaling pathways, such as notch signaling, mediate the differentiation of hematopoietic stem cells, development of the immune system, and peripheral immune responses. Curr Stem Cell Res Ther (2011) 6:131-41. doi:10.2174/157488811795495459

65. Guo S, Lu J, Schlanger R, Zhang H, Wang JY, Fox MC, et al. MicroRNA miR125a controls hematopoietic stem cell number. Proc Natl Acad Sci U S A (2010) 107:14229-34. doi:10.1073/pnas.0913574107

66. Gangaraju VK, Lin H. MicroRNAs: key regulators of stem cells. Nat Rev Mol Cell Biol (2009) 10:116-25. doi:10.1038/nrm2621

67. O'Connell RM, Chaudhuri AA, Rao DS, Gibson WS, Balazs AB, Baltimore D. MicroRNAs enriched in hematopoietic stem cells differentially regulate longterm hematopoietic output. Proc Natl Acad Sci U S A (2010) 107:14235-40. doi:10.1073/pnas.1009798107

68. Hong SH, Kim KS, Oh IH. Concise review: exploring mirnas-toward a better understanding of hematopoiesis. Stem Cells (2015) 33:1-7. doi:10.1002/ stem. 1810

69. Lazare SS, Wojtowicz EE, Bystrykh LV, de Haan G. microRNAs in hematopoiesis. Exp Cell Res (2014) 329:234-8. doi:10.1016/j.yexcr.2014.08. 033

70. Khalaj M, Tavakkoli M, Stranahan AW, Park CY. Pathogenic microRNA's in myeloid malignancies. Front Genet (2014) 5:361. doi:10.3389/fgene.2014. 00361

71. Bottoni A, Calin GA. MicroRNAs as main players in the pathogenesis of chronic lymphocytic leukemia. Microrna (2014) 2:158-64. doi:10.2174/ 2211536602666131126002337

72. Agirre X, Martínez-Climent JÁ, Odero MD, Prósper F. Epigenetic regulation of miRNA genes in acute leukemia. Leukemia (2012) 26:395-403. doi:10.1038/ leu.2011.344

73. Gounaris-Shannon S, Chevassut T. The role of miRNA in haematological malignancy. Bone Marrow Res (2013) 2013:269107. doi:10.1155/2013/269107

74. Bourguignon LY, Wong G, Earle C, Chen L. Hyaluronan-CD44v3 interaction with Oct4-Sox2-Nanog promotes miR-302 expression leading to self-renewal, clonal formation, and cisplatin resistance in cancer stem cells from head and neck squamous cell carcinoma. J Biol Chem (2012) 287:32800-24. doi:10.1074/ jbc.M111.308528

75. Liu H, Deng S, Zhao Z, Zhang H, Xiao J, Song W, et al. Oct4 regulates the miR-302 cluster in P19 mouse embryonic carcinoma cells. Mol Biol Rep (2011) 38:2155-60. doi:10.1007/s11033-010-0343-4

76. Bao W, Fu HJ, Xie QS, Wang L, Zhang R, Guo ZY, et al. HER2 interacts with CD44 to up-regulate CXCR4 via epigenetic silencing of microRNA-139 in gastric cancer cells. Gastroenterology (2011) 141:2076-87. doi:10.1053/j. gastro.2011.08.050

77. Bourguignon LY, Spevak CC, Wong G, Xia W, Gilad E. Hyaluronan-CD44 interaction with protein kinase $\mathrm{C}$ (epsilon) promotes oncogenic signaling by the stem cell marker Nanog and the production of microRNA-21, leading to down-regulation of the tumor suppressor protein PDCD4, anti-apoptosis, and chemotherapy resistance in breast tumor cells. J Biol Chem (2009) 284:26533-46. doi:10.1074/jbc.M109.027466

78. Rana S, Malinowska K, Zöller M. Exosomal tumor microRNA modulates premetastatic organ cells. Neoplasia (2013) 15:281-95. doi:10.1593/neo. 122010

79. Medina PP, Nolde M, Slack FJ. OncomiR addiction in an in vivo model of microRNA-21-induced pre-B-cell lymphoma. Nature (2010) 467:86-90. doi:10.1038/nature09284

80. Hu H, Li Y, Gu J, Zhu X, Dong D, Yao J, et al. Antisense oligonucleotide against miR-21 inhibits migration and induces apoptosis in leukemic K562 cells. Leuk Lymphoma (2010) 51:694-701. doi:10.3109/10428191003596835

81. Klingbeil P, Marhaba R, Jung T, Kirmse R, Ludwig T, Zöller M. CD44 variant isoforms promote metastasis formation by a tumor cell-matrix cross-talk that supports adhesion and apoptosis resistance. Mol Cancer Res (2009) 7:168-79. doi:10.1158/1541-7786.MCR-08-0207

82. Liu C, Kelnar K, Liu B, Chen X, Calhoun-Davis T, Li H, et al. The microRNA miR-34a inhibits prostate cancer stem cells and metastasis by directly repressing CD44. Nat Med (2011) 17:211-5. doi:10.1038/nm.2284

83. Ali S, Almhanna K, Chen W, Philip PA, Sarkar FH. Differentially expressed miRNAs in the plasma may provide a molecular signature for aggressive pancreatic cancer. Am J Transl Res (2010) 3:28-47.

84. Liu L, Jiang Y, Zhang H, Greenlee AR, Han Z. Overexpressed miR494 down-regulates PTEN gene expression in cells transformed by 
antibenzo(a)pyrene-trans-7,8-dihydrodiol-9,10-epoxide. Life Sci (2010) 86:192-8. doi:10.1016/j.lfs.2009.12.002

85. Qin W, Shi Y, Zhao B, Yao C, Jin L, Ma J, et al. miR-24 regulates apoptosis by targeting the open reading frame (ORF) region of FAF1 in cancer cells. PLoS One (2010) 5:e9429. doi:10.1371/journal.pone.0009429

86. Jung T, Castellana D, Klingbeil P, Cuesta Hernández I, Vitacolonna M, Orlicky DJ, et al. CD44v6 dependence of premetastatic niche preparation by exosomes. Neoplasia (2009) 11:1093-105. doi:10.1593/neo.09822

87. Garofalo M, Romano G, Di Leva G, Nuovo G, Jeon YJ, Ngankeu A, et al. EGFR and MET receptor tyrosine kinase-altered microRNA expression induces tumorigenesis and gefitinib resistance in lung cancers. Nat Med (2011) 18:74-82. doi:10.1038/nm.2577

88. Cheng W, Liu T, Wan X, Gao Y, Wang H. MicroRNA-199a targets CD44 to suppress the tumorigenicity and multidrug resistance of ovarian cancerinitiating cells. FEBS J (2012) 279:2047-59. doi:10.1111/j.1742-4658.2012. 08589.x

89. Wang SH, Zhou JD, He QY, Yin ZQ, Cao K, Luo CQ. MiR-199a inhibits the ability of proliferation and migration by regulating CD44-Ezrin signaling in cutaneous squamous cell carcinoma cells. Int J Clin Exp Pathol (2014) 7:7131-41.

90. Rutnam ZJ, Yang BB. The non-coding $3^{\prime}$ UTR of CD44 induces metastasis by regulating extracellular matrix functions. J Cell Sci (2012) 125(Pt 8):2075-85. doi: $10.1242 /$ jcs 100818

91. Huang Q, Gumireddy K, Schrier M, le Sage C, Nagel R, Nair S, et al. The microRNAs miR-373 and miR-520c promote tumour invasion and metastasis. Nat Cell Biol (2008) 10:202-10. doi:10.1038/ncb1681

92. Skotheim RI, Nees M. Alternative splicing in cancer: noise, functional, or systematic? Int J Biochem Cell Biol (2007) 39:1432-49. doi:10.1016/j.biocel. 2007.02.016

93. Srebrow A, Kornblihtt AR. The connection between splicing and cancer. J Cell Sci (2006) 119:2635-41. doi:10.1242/jcs.03053

94. Schmits R, Filmus J, Gerwin N, Senaldi G, Kiefer F, Kundig T, et al. CD44 regulates hematopoietic progenitor distribution, granuloma formation, and tumorigenicity. Blood (1997) 90:2217-33.

95. Ghazi-Visser L, Laman JD, Nagel S, van Meurs M, van Riel D, Tzankov A, et al. CD44 variant isoforms control experimental autoimmune encephalomyelitis by affecting the lifespan of the pathogenic T cells. FASEB J (2013) 27:3683-701. doi:10.1096/fj.13-228809

96. Wittig BM, Johansson B, Zöller M, Schwärzler C, Günthert U. Abrogation of experimental colitis correlates with increased apoptosis in mice deficient for CD44 variant exon 7 (CD44v7). J Exp Med (2000) 191:2053-64. doi:10.1084/ jem.191.12.2053

97. Christ O, Günthert U, Haas R, Zöller M. Importance of CD44v7 isoforms for homing and seeding of hematopoietic progenitor cells. J Leukoc Biol (2001) 69:343-52.

98. Christ O, Günthert U, Schmidt DS, Zöller M. Allogeneic reconstitution after nonmyeloablative conditioning: mitigation of graft-versus-host and hostversus-graft reactivity by anti-CD44v6. J Leukoc Biol (2002) 71:33-46.

99. Lobo NA, Shimono Y, Qian D, Clarke MF. The biology of cancer stem cells. Annu Rev Cell Dev Biol (2007) 23:675-88. doi:10.1146/annurev.cellbio.22. 010305.104154

100. Krause DS, Lazarides K, von Andrian UH, Van Etten RA. Requirement for CD44 in homing and engraftment of BCR-ABL-expressing leukemic stem cells. Nat Med (2006) 12:1175-80. doi:10.1038/nm1489

101. Jin L, Hope KJ, Zhai Q, Smadja-Joffe F, Dick JE. Targeting of CD44 eradicates human acute myeloid leukemic stem cells. Nat Med (2006) 12:1167-74. doi:10. 1038/nm1483

102. Miyake K, Medina KL, Hayashi S, Ono S, Hamaoka T, Kincade PW. Monoclonal antibodies to Pgp-1/CD44 block lympho-hemopoiesis in longterm bone marrow cultures. J Exp Med (1990) 171:477-88. doi:10.1084/jem. 171.2.477

103. Mosaad YM. Hematopoietic stem cells: an overview. Transfus Apher Sci (2014) 51:68-82. doi:10.1016/j.transci.2014.10.016

104. Wolpert L. One hundred years of positional information. Trends Genet (1996) 12:359-64. doi:10.1016/S0168-9525(96)80019-9

105. Li L, Neaves WB. Normal stem cells and cancer stem cells: the niche matters. Cancer Res (2006) 66:4553-7. doi:10.1158/0008-5472.CAN-05-3986
106. Diaz-Flores L Jr, Madrid JF, Gutierrez R, Varela F, Alvarez-Argüelles H, DiazFlores L. Adult stem and transit-amplifying cell location. Histol Histopathol (2006) 21:995-1027.

107. Morrison SJ, Spradling AC. Stem cells and niches: mechanisms that promote stem cell maintenance throughout life. Cell (2008) 132:598-611. doi:10.1016/ j.cell.2008.01.038

108. Hendrix MJ, Seftor EA, Seftor RE, Kasemeier-Kulesa J, Kulesa PM, Postovit LM. Reprogramming metastatic tumour cells with embryonic microenvironments. Nat Rev Cancer (2007) 7:246-55. doi:10.1038/nrc2108

109. Schofield R. The relationship between the spleen colony-forming cell and the haemopoietic stem cell. Blood Cells (1978) 4:7-25.

110. Zhang J, Niu C, Ye L, Huang H, He X, Tong WG, et al. Identification of the haematopoietic stem cell niche and control of the niche size. Nature (2003) 425:836-41. doi:10.1038/nature02041

111. Owen M, Friedenstein AJ. Stromal stem cells: marrow-derived osteogenic precursors. Ciba Found Symp (1988) 136:42-60.

112. Tabe Y, Konopleva M. Advances in understanding the leukaemia microenvironment. Br J Haematol (2014) 164:767-78. doi:10.1111/bjh.12725

113. Reinisch A, Etchart N, Thomas D, Hofmann NA, Fruehwirth M, Sinha S, et al. Epigenetic and in vivo comparison of diverse MSC sources reveals an endochondral signature for human hematopoietic niche formation. Blood (2014) 125(2):249-60. doi:10.1182/blood-2014-04-572255

114. Yoshihara H, Arai F, Hosokawa K, Hagiwara T, Takubo K, Nakamura Y, et al. Thrombopoietin/MPL signaling regulates hematopoietic stem cell quiescence and interaction with the osteoblastic niche. Cell Stem Cell (2007) 1:685-97. doi:10.1016/j.stem.2007.10.020

115. Sugiyama T, Kohara H, Noda M, Nagasawa T. Maintenance of the hematopoietic stem cell pool by CXCL12-CXCR4 chemokine signaling in bone marrow stromal cell niches. Immunity (2006) 25:977-88. doi:10.1016/j.immuni.2006. 10.016

116. Stier S, Ko Y, Forkert R, Lutz C, Neuhaus T, Grünewald E, et al. Osteopontin is a hematopoietic stem cell niche component that negatively regulates stem cell pool size. J Exp Med (2005) 201:1781-91. doi:10.1084/jem. 20041992

117. Askmyr M, Sims NA, Martin TJ, Purton LE. What is the true nature of the osteoblastic hematopoietic stem cell niche? Trends Endocrinol Metab (2009) 20:303-9. doi:10.1016/j.tem.2009.03.004

118. Kiel MJ, Yilmaz OH, Iwashita T, Yilmaz OH, Terhorst C, Morrison SJ. SLAM family receptors distinguish hematopoietic stem and progenitor cells and reveal endothelial niches for stem cells. Cell (2005) 121:1109-21. doi:10.1016/ j.cell.2005.05.026

119. Doan PL, Chute JP. The vascular niche: home for normal and malignant hematopoietic stem cells. Leukemia (2012) 26:54-62. doi:10.1038/leu.2011.236

120. Balduino A, Mello-Coelho V, Wang Z, Taichman RS, Krebsbach PH, Weeraratna AT, et al. Molecular signature and in vivo behavior of bone marrow endosteal and subendosteal stromal cell populations and their relevance to hematopoiesis. Exp Cell Res (2012) 318:2427-37. doi:10.1016/j.yexcr.2012. 07.009

121. Stern R. Association between cancer and "acid mucopolysaccharides": an old concept comes of age, finally. Semin Cancer Biol (2008) 18:238-43. doi:10. 1016/j.semcancer.2008.03.014

122. Khaldoyanidi SK, Goncharova V, Mueller B, Schraufstatter IU. Hyaluronan in the healthy and malignant hematopoietic microenvironment. Adv Cancer Res (2014) 123:149-89. doi:10.1016/B978-0-12-800092-2.00006-X

123. Szczepanek K, Kieda C, Cichy J. Differential binding of hyaluronan on the surface of tissue-specific endothelial cell lines. Acta Biochim Pol (2008) 55:35-42.

124. Winkler CW, Foster SC, Matsumoto SG, Preston MA, Xing R, Bebo BF, et al. Hyaluronan anchored to activated CD44 on central nervous system vascular endothelial cells promotes lymphocyte extravasation in experimental autoimmune encephalomyelitis. J Biol Chem (2012) 287:33237-51. doi:10. 1074/jbc.M112.356287

125. Wang N, Tytell JD, Ingber DE. Mechanotransduction at a distance: mechanically coupling the extracellular matrix with the nucleus. Nat Rev Mol Cell Biol (2009) 10:75-82. doi:10.1038/nrm2594

126. Itano N, Kimata K. Altered hyaluronan biosynthesis in cancer progression. Semin Cancer Biol (2008) 18:268-74. doi:10.1016/j.semcancer.2008.03.006 
127. Girish KS, Kemparaju K. The magic glue hyaluronan and its eraser hyaluronidase: a biological overview. Life Sci (2007) 80:1921-43. doi:10.1016/ j.lfs.2007.02.037

128. Kuhn NZ, Tuan RS. Regulation of stemness and stem cell niche of mesenchymal stem cells: implications in tumorigenesis and metastasis. J Cell Physiol (2010) 222:268-77. doi:10.1002/jcp.21940

129. Adamia S, Maxwell CA, Pilarski LM. Hyaluronan and hyaluronan synthases: potential therapeutic targets in cancer. Curr Drug Targets Cardiovasc Haematol Disord (2005) 5:3-14. doi:10.2174/1568006053005056

130. Jung T, Gross W, Zöller M. CD44v6 coordinates tumor matrix-triggered motility and apoptosis resistance. J Biol Chem (2011) 286:15862-74. doi:10. 1074/jbc.M110.208421

131. Couchman JR. Transmembrane signaling proteoglycans. Annu Rev Cell Dev Biol (2010) 26:89-114. doi:10.1146/annurev-cellbio-100109-104126

132. Weber GF. Molecular mechanisms of metastasis. Cancer Lett (2008) 270:181-90. doi:10.1016/j.canlet.2008.04.030

133. Katagiri YU, Sleeman J, Fujii H, Herrlich P, Hotta H, Tanaka K, et al. CD44 variants but not CD44s cooperate with betal-containing integrins to permit cells to bind to osteopontin independently of arginine-glycine-aspartic acid, thereby stimulating cell motility and chemotaxis. Cancer Res (1999) 59:219-26.

134. Kim MS, Park MJ, Moon EJ, Kim SJ, Lee CH, Yoo H, et al. Hyaluronic acid induces osteopontin via the phosphatidylinositol 3-kinase/Akt pathway to enhance the motility of human glioma cells. Cancer Res (2005) 65:686-91.

135. Kollet O, Dar A, Shivtiel S, Kalinkovich A, Lapid K, Sztainberg Y, et al. Osteoclasts degrade endosteal components and promote mobilization of hematopoietic progenitor cells. Nat Med (2006) 12:657-64. doi:10.1038/ $\mathrm{nm} 1417$

136. Weber GF, Bronson RT, Ilagan J, Cantor H, Schmits R, Mak TW. Absence of the CD44 gene prevents sarcoma metastasis. Cancer Res (2002) 62:2281-6.

137. Erb U, Megaptche AP, Gu X, Büchler MW, Zöller M. CD44 standard and CD44v10 isoform expression on leukemia cells distinctly influences niche embedding of hematopoietic stem cells. J Hematol Oncol (2014) 7:29. doi:10. 1186/1756-8722-7-29

138. van der Voort R, Taher TE, Wielenga VJ, Spaargaren M, Prevo R, Smit L, et al. Heparan sulfate-modified CD44 promotes hepatocyte growth factor/scatter factor-induced signal transduction through the receptor tyrosine kinase c-Met. J Biol Chem (1999) 274:6499-506. doi:10.1074/jbc.274.10.6499

139. Orian-Rousseau V, Chen L, Sleeman JP, Herrlich P, Ponta H. CD44 is required for two consecutive steps in HGF/c-Met signaling. Genes Dev (2002) 16:3074-86. doi:10.1101/gad.242602

140. Imanirad P, Dzierzak E. Hypoxia and HIFs in regulating the development of the hematopoietic system. Blood Cells Mol Dis (2013) 51:256-63. doi:10.1016/ j.bcmd.2013.08.005

141. Poulos MG, Gars EJ, Gutkin MC, Kloss CC, Ginsberg M, Scandura JM, et al. Activation of the vascular niche supports leukemic progression and resistance to chemotherapy. Exp Hematol (2014) 42:976.e-86.e. doi:10.1016/j.exphem. 2014.08.003

142. Rosu-Myles M, Stewart E, Trowbridge J, Ito CY, Zandstra P, Bhatia M. A unique population of bone marrow cells migrates to skeletal muscle via hepatocyte growth factor/c-met axis. J Cell Sci (2005) 118:4343-52. doi:10.1242/ jcs. 02555

143. Sherman L, Wainwright D, Ponta H, Herrlich P. A splice variant of CD44 expressed in the apical ectodermal ridge presents fibroblast growth factors to limb mesenchyme and is required for limb outgrowth. Genes Dev (1998) 12:1058-71. doi:10.1101/gad.12.7.1058

144. Lee SK, Kim Y, Kim SS, Lee JH, Cho K, Lee SS, et al. Differential expression of cell surface proteins in human bone marrow mesenchymal stem cells cultured with or without basic fibroblast growth factor containing medium. Proteomics (2009) 9:4389-405. doi:10.1002/pmic.200900165

145. Berdiaki A, Nikitovic D, Tsatsakis A, Katonis P, Karamanos NK, Tzanakakis GN. bFGF induces changes in hyaluronan synthase and hyaluronidase isoform expression and modulates the migration capacity of fibrosarcoma cells. Biochim Biophys Acta (2009) 1790:1258-65. doi:10.1016/j.bbagen.2009. 06.013

146. Zhang J, Ren H, Yuan P, Lang W, Zhang L, Mao L. Down-regulation of hepatoma-derived growth factor inhibits anchorage-independent growth and invasion of non-small cell lung cancer cells. Cancer Res (2006) 66:18-23. doi:10.1158/0008-5472.CAN-04-3905
147. Pucci S, Mazzarelli P, Nucci C, Ricci F, Spagnoli L. G. CLU "in and out": looking for a link. Adv Cancer Res (2009) 105:93-113. doi:10.1016/S0065-230X(09) 05006-4

148. Ratajczak MZ, Kim C, Ratajczak J, Janowska-Wieczorek A. Innate immunity as orchestrator of bone marrow homing for hematopoietic stem/progenitor cells. Adv Exp Med Biol (2013) 735:219-32. doi:10.1007/978-1-4614-4118-2_15

149. Desai B, Ma T, Zhu J, Chellaiah MA. Characterization of the expression of variant and standard CD44 in prostate cancer cells: identification of the possible molecular mechanism of CD44/MMP9 complex formation on the cell surface. J Cell Biochem (2009) 108:272-84. doi:10.1002/jcb.22248

150. Miletti-González KE, Murphy K, Kumaran MN, Ravindranath AK, Wernyj $\mathrm{RP}$, Kaur S, et al. Identification of function for CD44 intracytoplasmic domain (CD44-ICD): modulation of matrix metalloproteinase 9 (MMP-9) transcription via novel promoter response element. J Biol Chem (2012) 287:18995-9007. doi:10.1074/jbc.M111.318774

151. Yu Q, Stamenkovic I. Localization of matrix metalloproteinase 9 to the cell surface provides a mechanism for CD44-mediated tumor invasion. Genes Dev (1999) 13:35-48. doi:10.1101/gad.13.1.35

152. Wilson TJ, Nannuru KC, Futakuchi M, Sadanandam A, Singh RK. Cathepsin G enhances mammary tumor-induced osteolysis by generating soluble receptor activator of nuclear factor-kappaB ligand. Cancer Res (2008) 68:5803-11. doi:10.1158/0008-5472.CAN-07-5889

153. Hill A, McFarlane S, Johnston PG, Waugh DJ. The emerging role of CD44 in regulating skeletal micrometastasis. Cancer Lett (2006) 237:1-9. doi:10.1016/ j.canlet.2005.05.006

154. Yu Q, Stamenkovic I. Cell surface-localized matrix metalloproteinase-9 proteolytically activates TGF-beta and promotes tumor invasion and angiogenesis. Genes Dev (2000) 14:163-76.

155. Wilson TJ, Nannuru KC, Singh RK. Cathepsin G-mediated activation of promatrix metalloproteinase 9 at the tumor-bone interface promotes transforming growth factor-beta signaling and bone destruction. Mol Cancer Res (2009) 7:1224-33. doi:10.1158/1541-7786.MCR-09-0028

156. Chen Q, Yuan Y, Chen T. Morphology, differentiation and adhesion molecule expression changes of bone marrow mesenchymal stem cells from acute myeloid leukemia patients. Mol Med Rep (2014) 9:293-8. doi:10.3892/mmr. 2013.1789

157. Almond A. Hyaluronan. Cell Mol Life Sci (2007) 64:1591-6. doi:10.1007/ s00018-007-7032-z

158. Toole BP. Hyaluronan: from extracellular glue to pericellular cue. Nat Rev Cancer (2004) 4:528-39. doi:10.1038/nrc1391

159. Lapidot T, Dar A, Kollet O. How do stem cells find their way home? Blood (2005) 106:1901-10. doi:10.1182/blood-2005-04-1417

160. Liu J, Jiang G. CD44 and hematologic malignancies. Cell Mol Immunol (2006) 3:359-65.

161. Lundell BI, Mccarthy JB, Kovach NL, Verfaillie CM. Activation of betal integrins on CML progenitors reveals cooperation between betal integrins and CD44 in the regulation of adhesion and proliferation. Leukemia (1997) 11:822-9. doi:10.1038/sj.leu.2400653

162. Carstanjen D, Gross A, Kosova N, Fichtner I, Salama A. The alpha4beta1 and alpha5beta1 integrins mediate engraftment of granulocyte-colony-stimulating factormobilized human hematopoietic progenitor cells. Transfusion (2005) 45:1192-200. doi:10.1111/j.1537-2995.2005.00172.x

163. Wierenga PK, Weersing E, Dontje B, de Haan G, van Os R. Differential role for very late antigen-5 in mobilization and homing of hematopoietic stem cells. Bone Marrow Transplant (2006) 38:789-97. doi:10.1038/sj.bmt.1705534

164. Marhaba R, Freyschmidt-Paul P, Zöller M. In vivo CD44- $\alpha 4 \beta 1$ complex formation in autoimmune disease has consequences on $\mathrm{T}$ cell activation and apoptosis resistance. Eur J Immunol (2006) 36:3017-32. doi:10.1002/eji. 200636158

165. Prosper F, Verfaillie CM. Regulation of hematopoiesis through adhesion receptors. J Leukoc Biol (2001) 69:307-16.

166. Ford CD, Greenwood J, Anderson J, Handrahan D, Petersen FB. Good and poor mobilizing patients differ in mobilized CD34+ cell adhesion molecule profiles. Transfusion (2004) 44:1769-73. doi:10.1111/j.0041-1132. 2004.04035.x

167. Christ O, Kronenwett R, Haas R, Zöller M. Combining G-CSF with a blockade of adhesion strongly improves the reconstitutive capacity of mobilized hematopoietic progenitor cells. Exp Hematol (2001) 29:380-90. doi:10.1016/ S0301-472X(00)00674-3 
168. Zohren F, Toutzaris D, Klärner V, Hartung HP, Kieseier B, Haas R. The monoclonal anti-VLA-4 antibody natalizumab mobilizes CD34+ hematopoietic progenitor cells in humans. Blood (2008) 111:3893-5. doi:10.1182/ blood-2007-10-120329

169. Zöller M, Rajasagi M, Vitacolonna M, Luft T. Thymus repopulation after allogeneic reconstitution in hematological malignancies. Exp Hematol (2007) 35:1891-905. doi:10.1016/j.exphem.2007.08.005

170. Krause DS, Fulzele K, Catic A, Sun CC, Dombkowski D, Hurley MP, et al. Differential regulation of myeloid leukemias by the bone marrow microenvironment. Nat Med (2013) 19:1513-7. doi:10.1038/nm.3364

171. Singh R. (2011). CD44 as a Hematopoietic Stem Cell Marker. Ph.D. thesis, Faculty of Chemistry and Biosciences, KIT, Karlsruhe, Germany.

172. Colmone A, Amorim M, Pontier AL, Wang S, Jablonski E, Sipkins DA. Leukemic cells create bone marrow niches that disrupt the behavior of normal hematopoietic progenitor cells. Science (2008) 322:1861-5. doi:10.1126/ science. 1164390

173. Khaldoyanidi S, Schnabel D, Föhr N, Zöller M. Functional activity of CD44 isoforms in haemopoiesis of the rat. Br J Haematol (1997) 96:31-45. doi:10. 1111/j.1365-2141.1997.tb00001.x

174. Thirupathi P. (2014) Contribution of CD44v6 and CD44v7 to the Crosstalk Between Hematopoietic Stem Cells and the Bone Marrow Niche. Ph.D. thesis, Faculty of Chemistry and Biosciences, KIT, Karlsruhe, Germany.

175. Richman CM, Weiner RS, Yankee RA. Increase in circulating stem cells following chemotherapy in man. Blood (1976) 47:1031-9.

176. Koike K, Ogawa M, Ihle JN, Miyake T, Shimizu T, Miyajima A, et al. Recombinant murine granulocyte-macrophage (GM) colony-stimulating factor supports formation of GM and multipotential blast cell colonies in culture: comparison with the effects of interleukin-3. J Cell Physiol (1987) 131:458-64. doi:10.1002/jcp.1041310319

177. Brugger W, Bross K, Frisch J, Dern P, Weber B, Mertelsmann R, et al. Mobilization of peripheral blood progenitor cells by sequential administration of interleukin-3 and granulocyte-macrophage colony-stimulating factor following polychemotherapy with etoposide, ifosfamide, and cisplatin. Blood (1992) 79:1193-200.

178. Liu F, Poursine-Laurent J, Link DC. Expression of the GCSF receptor on hematopoietic progenitor cells is not required for their mobilization by G-CSF. Blood (2000) 95:3025-31.

179. Winkler IG, Sims NA, Pettit AR, Barbier V, Nowlan B, Helwani F, et al. Bone marrow macrophages maintain hematopoietic stem cell (HSC) niches and their depletion mobilizes HSCs. Blood (2010) 116:4815-28. doi:10.1182/ blood-2009-11-253534

180. Christopher MJ, Liu F, Hilton MJ, Long F, Link DC. Suppression of CXCL12 production by bone marrow osteoblasts is a common and critical pathway for cytokine induced mobilization. Blood (2009) 114:1331-9. doi:10.1182/ blood-2008-10-184754

181. Goichberg P, Kalinkovich A, Borodovsky N, Tesio M, Petit I, Nagler A, et al. cAMP-induced PKCzeta activation increases functional CXCR4 expression on human CD34+ hematopoietic progenitors. Blood (2006) 107:870-9. doi:10. 1182/blood-2005-03-0941

182. Peled A, Petit I, Kollet O, Magid M, Ponomaryov T, Byk T, et al. Dependence of human stem cell engraftment and repopulation of NOD/ SCID mice on CXCR4. Science (1999) 283:845-8. doi:10.1126/science.283. 5403.845

183. Petit I, Szyper-Kravitz M, Nagler A, Lahav M, Peled A, Habler L, et al. GCSF induces stem cell mobilization by decreasing bone marrow SDF-1 and up-regulating CXCR4. Nat Immunol (2002) 3:687-94. doi:10.1038/ni813

184. Bonig H, Papayannopoulou T. Mobilization of hematopoietic stem/progenitor cells: general principles and molecular mechanisms. Methods Mol Biol (2012) 904:1-14. doi:10.1007/978-1-61779-943-3_1

185. Levesque JP, Liu F, Simmons PJ, Betsuyaku T, Senior RM, Pham C, et al. Characterization of hematopoietic progenitor mobilization in protease-deficient mice. Blood (2004) 104:65-72. doi:10.1182/blood-2003-05-1589

186. Christopherson KWII, Cooper S, Hangoc G, Broxmeyer HE. CD26 is essential for normal G-CSF-induced progenitor cell mobilization as determined by CD26-/- mice. Exp Hematol (2003) 31:1126-34. doi:10.1016/j.exphem.2003. 07.002

187. Levesque J, Takamatsu T, Nilsson SK, Haylock DN, Simmons PJ. Vascular cell adhesion molecule-1 (CD106) is cleaved by neutrophil proteases in the bone marrow following hematopoietic progenitor cell mobilization by granulocyte colony-stimulating factor. Blood (2001) 98:1289-97. doi:10.1182/ blood.V98.5.1289

188. Vagima Y, Avigdor A, Goichberg P, Shivtiel S, Tesio M, Kalinkovich A, et al. MT1-MMP and RECK are involved in human CD34+ progenitor cell retention, egress, and mobilization. J Clin Invest (2009) 119:492-503. doi:10. 1172/JCI36541

189. Avigdor A, Goichberg P, Shivtiel S, Dar A, Peled A, Samira S, et al. CD44 and hyaluronic acid cooperate with SDF-1 in the trafficking of human CD34+ stem/progenitor cells to bone marrow. Blood (2004) 103:2981-9. doi:10.1182/ blood-2003-10-3611

190. Ratajczak MZ, Reca R, Wysoczynski M, Kucia M, Baran JT, Allendorf DJ, et al. Transplantation studies in C3-deficient animals reveal a novel role of the third complement component (C3) in engraftment of bone marrow cells. Leukemia (2004) 18:1482-90. doi:10.1038/sj.leu.2403446

191. Tjwa M, Janssens S, Carmeliet P. Plasmin therapy enhances mobilization of HPCs after G-CSF. Blood (2008) 112:4048-50. doi:10.1182/blood2008-07-166587

192. Basak P, Chatterjee S, Das M, Das P, Pereira JA, Dutta RK, et al. Phenotypic alteration of bone marrow HSC and microenvironmental association in experimentally induced leukemia. Curr Stem Cell Res Ther (2010) 5:379-86. doi:10.2174/157488810793351677

193. Chellaiah MA, Ma T. Membrane localization of membrane type 1 matrix metalloproteinase by CD44 regulates the activation of pro-matrix metalloproteinase 9 in osteoclasts. Biomed Res Int (2013) 2013:302392. doi:10.1155/2013/ 302392

194. Raaijmakers MH. Regulating traffic in the hematopoietic stem cell niche. Haematologica (2010) 95:1439-41. doi:10.3324/haematol.2010.027342

195. Sipkins DA, Wei X, Wu JW, Runnels JM, Côté D, Means TK, et al. In vivo imaging of specialized bone marrow endothelial microdomains for tumour engraftment. Nature (2005) 435:969-73. doi:10.1038/nature03703

196. Lesley J, English NM, Gál I, Mikecz K, Day AJ, Hyman R. Hyaluronan binding properties of a CD44 chimera containing the link module of TSG-6. J Biol Chem (2002) 277:26600-8. doi:10.1074/jbc.M201068200

197. Katayama Y, Hidalgo A, Chang J, Peired A, Frenette PS. CD44 is a physiological E-selectin ligand on neutrophils. J Exp Med (2005) 201:1183-9. doi:10.1084/ jem.20042014

198. Papayannopoulou T, Craddock C, Nakamoto B, Priestley GV, Wolf NS. The VLA4/VCAM-1 adhesion pathway defines contrasting mechanisms of lodgement of transplanted murine hemopoietic progenitors between bone marrow and spleen. Proc Natl Acad Sci U S A (1995) 92:9647-51. doi:10.1073/pnas.92. 21.9647

199. Lévesque JP, Leavesley DI, Niutta S, Vadas M, Simmons PJ. Cytokines increase human hemopoietic cell adhesiveness by activation of very late antigen (VLA)4 and VLA-5 integrins. J Exp Med (1995) 181:1805-15. doi:10.1084/jem.181. 5.1805

200. Mazo IB, Gutierrez-Ramos JC, Frenette PS, Hynes RO, Wagner DD, von Andrian UH. Hematopoietic progenitor cell rolling in bone marrow microvessels: parallel contributions by endothelial selectins and vascular cell adhesion molecule 1. J Exp Med (1998) 188:465-74. doi:10.1084/jem.188.3.465

201. Katayama Y, Hidalgo A, Furie BC, Vestweber D, Furie B, Frenette PS. PSGL1 participates in E-selectin-mediated progenitor homing to bone marrow: evidence for cooperation between E-selectin ligands and alpha4 integrin. Blood (2003) 102:2060-7. doi:10.1182/blood-2003-04-1212

202. Siegelman MH, Stanescu D, Estess P. The CD44-initiated pathway of T-cell extravasation uses VLA-4 but not LFA-1 for firm adhesion. J Clin Invest (2000) 105:683-91. doi:10.1172/JCI8692

203. Lamontagne CA, Grandbois M. PKC-induced stiffening of hyaluronan/CD44 linkage; local force measurements on glioma cells. Exp Cell Res (2008) 314:227-36. doi:10.1016/j.yexcr.2007.07.013

204. Thomas L, Byers HR, Vink J, Stamenkovic I. CD44H regulates tumor cell migration on hyaluronate-coated substrate. J Cell Biol (1992) 118:971-7. doi:10.1083/jcb.118.4.971

205. Oliferenko S, Kaverina I, Small JV, Huber LA. Hyaluronic acid (HA) binding to CD44 activates Rac1 and induces lamellipodia outgrowth. J Cell Biol (2000) 148:1159-64. doi:10.1083/jcb.148.6.1159

206. Bustelo XR. Regulatory and signaling properties of the Vav family. Mol Cell Biol (2000) 20:1461-77. doi:10.1128/MCB.20.5.1461-1477.2000

207. Bourguignon LY, Singleton PA, Zhu H, Diedrich F. Hyaluronan-mediated CD44 interaction with RhoGEF and Rho kinase promotes Grb2-associated 
binder-1 phosphorylation and phosphatidylinositol 3-kinase signaling leading to cytokine (macrophage-colony stimulating factor) production and breast tumor progression. J Biol Chem (2003) 278:29420-34. doi:10.1074/jbc. M301885200

208. Bourguignon LY. Hyaluronan-mediated CD44 activation of RhoGTPase signaling and cytoskeleton function promotes tumor progression. Semin Cancer Biol (2008) 18:251-9. doi:10.1016/j.semcancer.2008.03.007

209. Singh V, Erb U, Zöller M. Cooperativity of CD44 and $\alpha 4 \beta 1$ in leukemia cell homing, migration, and survival offers a means for therapeutic attack. J Immunol (2013) 191:5304-16. doi:10.4049/jimmunol.1301543

210. Nagano O, Saya H. Mechanism and biological significance of CD44 cleavage. Cancer Sci (2004) 95:930-5. doi:10.1111/j.1349-7006.2004.tb03179.x

211. Nakamura H, Suenaga N, Taniwaki K, Matsuki H, Yonezawa K, Fujii M, et al. Constitutive and induced CD44 shedding by ADAM-like proteases and membrane-type 1 matrix metalloproteinase. Cancer Res (2004) 64:876-82. doi:10.1158/0008-5472.CAN-03-3502

212. Sugahara KN, Hirata T, Tanaka T, Ogino S, Takeda M, Terasawa H, et al. Chondroitin sulfate $\mathrm{E}$ fragments enhance CD44 cleavage and CD44-dependent motility in tumor cells. Cancer Res (2008) 68:7191-9. doi:10.1158/0008-5472. CAN-07-6198

213. Krause DS, Lazarides K, Lewis JB, von Andrian UH, Van Etten RA. Selectins and their ligands are required for homing and engraftment of BCR-ABL1+ leukemic stem cells in the bone marrow niche. Blood (2014) 123:1361-71. doi:10.1182/blood-2013-11-538694

214. Ratajczak MZ, Kucia M, Majka M, Reca R, Ratajczak J. Heterogeneous populations of bone marrow stem cells - are we spotting on the same cells from the different angles? Folia Histochem Cytobiol (2004) 42:139-46.

215. Yang L, Wang L, Geiger H, Cancelas JA, Mo J, Zheng Y. Rho GTPase Cdc42 coordinates hematopoietic stem cell quiescence and niche interaction in the bone marrow. Proc Natl Acad Sci U S A (2007) 104:5091-6. doi:10.1073/pnas. 0610819104

216. Vaiselbuh SR, Edelman M, Lipton JM, Liu JM. Ectopic human mesenchymal stem cell-coated scaffolds in NOD/SCID mice: an in vivo model of the leukemia niche. Tissue Eng Part C Methods (2010) 16:1523-31. doi:10.1089/ ten.tec.2010.0179

217. Tavor S, Petit I. Can inhibition of the SDF-1/CXCR4 axis eradicate acute leukemia? Semin Cancer Biol (2010) 20:178-85. doi:10.1016/j.semcancer.2010. 07.001

218. Naor D, Sionov RV, Ish-Shalom D. CD44: structure, function, and association with the malignant process. Adv Cancer Res (1997) 71:241-319.

219. Yamamura K, Ohishi K, Katayama N, Kato K, Shibasaki T, Sugimoto Y. Notch ligand Delta-1 differentially modulates the effects of gp130 activation on interleukin-6 receptor alpha-positive and -negative human hematopoietic progenitors. Cancer Sci (2007) 98:1597-603. doi:10.1111/j.1349-7006.2007. 00566.x

220. Nervi B, Link DC, DiPersio JF. Cytokines and hematopoietic stem cell mobilization. J Cell Biochem (2006) 99:690-705. doi:10.1002/jcb.21043

221. de Barros AP, Takiya CM, Garzoni LR, Leal-Ferreira ML, Dutra HS, Chiarini LB, et al. Osteoblasts and bone marrow mesenchymal stromal cells control hematopoietic stem cell migration and proliferation in $3 \mathrm{D}$ in vitro model. PLoS One (2010) 5:e9093. doi:10.1371/journal.pone.0009093

222. Nilsson SK, Johnston HM, Whitty GA, Williams B, Webb RJ, Denhardt DT, et al. Osteopontin, a key component of the hematopoietic stem cell niche and regulator of primitive hematopoietic progenitor cells. Blood (2005) 106:1232-9. doi:10.1182/blood-2004-11-4422

223. Lee H, Ratajczak MZ. Innate immunity: a key player in the mobilization of hematopoietic stem/progenitor cells. Arch Immunol Ther Exp (2009) 57:269-78. doi:10.1007/s00005-009-0037-6

224. Asosingh K, Günthert U, Bakkus MH, De Raeve H, Goes E, Van Riet I, et al. In vivo induction of insulin-like growth factor-I receptor and CD44v6 confers homing and adhesion to murine multiple myeloma cells. Cancer Res (2000) 60:3096-104.

225. Ponta H, Sherman L, Herrlich PA. CD44: from adhesion molecules to signalling regulators. Nat Rev Mol Cell Biol (2003) 4:33-45. doi:10.1038/nrm1004

226. Marhaba R, Zöller M. CD44 in cancer progression: adhesion, migration and growth regulation. J Mol Histol (2004) 35:211-31. doi:10.1023/B:HIJ. 0000032354.94213 .69
227. Pap E, Pállinger E, Pásztói M, Falus A. Highlights of a new type of intercellular communication: microvesicle-based information transfer. Inflamm Res (2009) 58:1-8. doi:10.1007/s00011-008-8210-7

228. Stanley S. Biological nanoparticles and their influence on organisms. Curr Opin Biotechnol (2014) 28:69-74. doi:10.1016/j.copbio.2013.11.014

229. Tadokoro H, Umezu T, Ohyashiki K, Hirano T, Ohyashiki JH. Exosomes derived from hypoxic leukemia cells enhance tube formation in endothelial cells. J Biol Chem (2013) 288:34343-51. doi:10.1074/jbc.M113.480822

230. Sato-Kuwabara Y, Melo SA, Soares FA, Calin GA. The fusion of two worlds: non-coding RNAs and extracellular vesicles - diagnostic and therapeutic implications (review). Int J Oncol (2015) 46:17-27. doi:10.3892/ijo.2014.2712

231. Ratajczak J, Miekus K, Kucia M, Zhang J, Reca R, Dvorak P, et al. Embryonic stem cell-derived microvesicles reprogram hematopoietic progenitors: evidence for horizontal transfer of mRNA and protein delivery. Leukemia (2006) 20:847-56. doi:10.1038/sj.leu.2404132

232. Okuyama K, Ogata J, Yamakawa N, Chanda B, Kotani A. Small RNA as a regulator of hematopoietic development, immune response in infection and tumorigenesis. Int J Hematol (2014) 99:553-60. doi:10.1007/ s12185-014-1564-4

233. Li L, Bhatia R. Stem cell quiescence. Clin Cancer Res (2011) 17:4936-41. doi:10.1158/1078-0432.CCR-10-1499

234. Arai $F$, Hirao A, Ohmura $M$, Sato $H$, Matsuoka $S$, Takubo $K$, et al. Tie2/angiopoietin-1 signaling regulates hematopoietic stem cell quiescence in the bone marrow niche. Cell (2004) 118:149-61. doi:10.1016/j.cell.2004.07.004

235. Blank U, Karlsson G, Karlsson S. Signaling pathways governing stem-cell fate. Blood (2008) 111:492-503. doi:10.1182/blood-2007-07-075168

236. Bourguignon LY, Singleton PA, Zhu H, Zhou B. Hyaluronan promotes signaling interaction between $\mathrm{CD} 44$ and the transforming growth factor beta receptor I in metastatic breast tumor cells. J Biol Chem (2002) 277:39703-12. doi:10.1074/jbc.M204320200

237. Basoni C, Reuzeau E, Croft D, Génot E, Kramer IM. CD44 and TGFbetal synergise to induce expression of a functional NADPH oxidase in promyelocytic cells. Biochem Biophys Res Commun (2006) 343:609-16. doi:10.1016/j. bbrc.2006.03.003

238. Robin C, Durand C. The roles of BMP and IL-3 signaling pathways in the control of hematopoietic stem cells in the mouse embryo. Int J Dev Biol (2010) 54:1189-200. doi:10.1387/ijdb.093040cr

239. Pimanda JE, Ottersbach K, Knezevic K, Kinston S, Chan WY, Wilson NK, et al. Gata2, Fli1, and Scl form a recursively wired gene-regulatory circuit during early hematopoietic development. Proc Natl Acad Sci U S A (2007) 104:17692-7. doi:10.1073/pnas.0707045104

240. Calvi LM, Adams GB, Weibrecht KW, Weber JM, Olson DP, Knight MC, et al. Osteoblastic cells regulate the haematopoietic stem cell niche. Nature (2003) 425:841-6. doi:10.1038/nature02040

241. Marshall CJ, Sinclair JC, Thrasher AJ, Kinnon C. Bone morphogenetic protein 4 modulates c-Kit expression and differentiation potential in murine embryonic aorta-gonad-mesonephros haematopoiesis in vitro. Br J Haematol (2007) 139:321-30. doi:10.1111/j.1365-2141.2007.06795.x

242. Peterson RS, Andhare RA, Rousche KT, Knudson W, Wang W, Grossfield JB, et al. CD44 modulates Smad1 activation in the BMP-7 signaling pathway. J Cell Biol (2004) 166:1081-91. doi:10.1083/jcb.200402138

243. Tanikawa R, Tanikawa T, Hirashima M, Yamauchi A, Tanaka Y. Galectin-9 induces osteoblast differentiation through the CD44/Smad signaling pathway. Biochem Biophys Res Commun (2010) 394:317-22. doi:10.1016/j.bbrc. 2010.02.175

244. Qian H, Buza-Vidas N, Hyland CD, Jensen CT, Antonchuk J, Månsson R, et al. Critical role of thrombopoietin in maintaining adult quiescent hematopoietic stem cells. Cell Stem Cell (2007) 1:671-84. doi:10.1016/j.stem. 2007.10.008

245. Kashiwakura I, Teramachi T, Kakizaki I, Takagi Y, Takahashi TA, Takagaki K. The effects of glycosaminoglycans on thrombopoietin-induced megakaryocytopoiesis. Haematologica (2006) 91:445-51.

246. Cain CJ, Manilay JO. Hematopoietic stem cell fate decisions are regulated by Wnt antagonists: comparisons and current controversies. Exp Hematol (2013) 41:3-16. doi:10.1016/j.exphem.2012.09.006

247. Cadigan KM, Nusse R. Wnt signaling: a common theme in animal development. Genes Dev (1997) 11:3286-305. doi:10.1101/gad.11.24.3286 
248. Pinson KI, Brennan J, Monkley S, Avery BJ, Skarnes WC. An LDL-receptorrelated protein mediates Wnt signalling in mice. Nature (2000) 407:535-8. doi: $10.1038 / 35035124$

249. Willert K, Nusse R. $\beta$-catenin: a key mediator of Wnt signaling. Curr Opin Genet Dev (1998) 8:95-102. doi:10.1016/S0959-437X(98)80068-3

250. MacDonald BT, Tamai K, He X. Wnt/beta-catenin signaling: components, mechanisms, and diseases. Dev Cell (2009) 17:9-26. doi:10.1016/j.devcel.2009. 06.016

251. Stathopoulos A, Iber D. Studies of morphogens: keep calm and carry on. Development (2013) 140:4119-24. doi:10.1242/dev.095141

252. MacDonald BT, Adamska M, Meisler MH. Hypomorphic expression of Dkk1 in the doubleridge mouse: dose dependence and compensatory interactions with Lrp6. Development (2004) 11:2543-52. doi:10.1242/dev.01126

253. Mao B, Wu W, Davidson G, Marhold J, Li M, Mechler BM, et al. Kremen proteins are Dickkopf receptors that regulate Wnt/beta-catenin signalling. Nature (2002) 6889:664-7. doi:10.1038/nature756

254. Fleming HE, Janzen V, Lo Celso C, Guo J, Leahy KM, Kronenberg HM, et al. Wnt signaling in the niche enforces hematopoietic stem cell quiescence and is necessary to preserve self-renewal in vivo. Cell Stem Cell (2008) 2:274-83. doi:10.1016/j.stem.2008.01.003

255. Yu X, Alder JK, Chun JH, Friedman AD, Heimfeld S, Cheng L, et al. HES1 inhibits cycling of hematopoietic progenitor cells via DNA binding. Stem Cells (2006) 4:876-88. doi:10.1634/stemcells.2005-0598

256. Duncan AW, Rattis FM, DiMascio LN, Congdon KL, Pazianos G, Zhao C, et al. Integration of Notch and Wnt signaling in hematopoietic stem cell maintenance. Nat Immunol (2005) 6:314-22. doi:10.1038/ni1164

257. Schmitt M, Metzger M, Gradl D, Davidson G, Orian-Rousseau V. CD44 functions in Wnt signaling by regulating LRP6 localization and activation. Cell Death Differ (2014) 22(4):677-89. doi:10.1038/cdd.2014.156

258. Grassinger J, Haylock DN, Storan MJ, Haines GO, Williams B, Whitty GA, et al. Thrombin-cleaved osteopontin regulates hemopoietic stem and progenitor cell functions through interactions with alpha9betal and alpha4beta1 integrins. Blood (2009) 114:49-59. doi:10.1182/blood-2009-01-197988

259. Yokasaki Y, Sheppard D. Mapping of the cryptic integrin-binding site in osteopontin suggests a new mechanism by which thrombin can regulate inflammation and tissue repair. Trends Cardiovasc Med (2000) 10:155-9. doi:10.1016/S1050-1738(00)00055-4

260. Jijiwa M, Demir H, Gupta S, Leung C, Joshi K, Orozco N, et al. CD44v6 regulates growth of brain tumor stem cells partially through the AKT-mediated pathway. PLoS One (2011) 6:e24217. doi:10.1371/journal.pone.0024217

261. Ara T, Nakamura Y, Egawa T, Sugiyama T, Abe K, Kishimoto T, et al. Impaired colonization of the gonads by primordial germ cells in mice lacking a chemokine, stromal cell-derived factor-1 (SDF-1). Proc Natl Acad Sci U S A (2003) 100:5319-23. doi:10.1073/pnas.0730719100

262. Zou YR, Kottmann AH, Kuroda M, Taniuchi I, Littman DR. Function of the chemokine receptor CXCR4 in haematopoiesis and in cerebellar development. Nature (1998) 393:595-9. doi:10.1038/31269

263. Lin ML, Lu YC, Chen HY, Lee CC, Chung JG, Chen SS. Suppressing the formation of lipid raft-associated Rac1/PI3K/Akt signaling complexes by curcumin inhibits SDF-1 $\alpha$-induced invasion of human esophageal carcinoma cells. Mol Carcinog (2014) 53:360-79. doi:10.1002/mc.21984

264. Ratajczak MZ, Lee H, Wysoczynski M, Wan W, Marlicz W, Laughlin MJ, et al. Novel insight into stem cell mobilization-plasma sphingosine-1-phosphate is a major chemoattractant that directs the egress of hematopoietic stem progenitor cells from the bone marrow and its level in peripheral blood increases during mobilization due to activation of complement cascade/membrane attack complex. Leukemia (2010) 24:976-85. doi:10.1038/leu.2010.53

265. Fuchs K, Hippe A, Schmaus A, Homey B, Sleeman JP, Orian-Rousseau V. Opposing effects of high- and low-molecular weight hyaluronan on CXCL12induced CXCR4 signaling depend on CD44. Cell Death Dis (2013) 4:e819. doi:10.1038/cddis.2013.364

266. Ellis SL, Grassinger J, Jones A, Borg J, Camenisch T, Haylock D, et al. The relationship between bone, hemopoietic stem cells, and vasculature. Blood (2011) 118:1516-24. doi:10.1182/blood-2010-08-303800

267. Schraufstatter IU, Serobyan N, Loring J, Khaldoyanidi SK. Hyaluronan is required for generation of hematopoietic cells during differentiation of human embryonic stem cells. J Stem Cells (2010) 5:9-21. doi:jsc.2010.5.1.9

268. Haylock DN, Nilsson SK. Stem cell regulation by the hematopoietic stem cell niche. Cell Cycle (2005) 4:1353-5. doi:10.4161/cc.4.10.2056
269. Wang A, de la Motte C, Lauer M, Hascall V. Hyaluronan matrices in pathobiological processes. FEBS J (2011) 278:1412-8. doi:10.1111/j.1742-4658.2011. 08069.x

270. Mohyeldin A, Garzón-Muvdi T, Quiñones-Hinojosa A. Oxygen in stem cell biology: a critical component of the stem cell niche. Cell Stem Cell (2010) 7:150-61. doi:10.1016/j.stem.2010.07.007

271. Schepers K, Pietras EM, Reynaud D, Flach J, Binnewies M, Garg T, et al. Myeloproliferative neoplasia remodels the endosteal bone marrow niche into a self-reinforcing leukemic niche. Cell Stem Cell (2013) 13:285-99. doi:10.1016/ j.stem.2013.06.009

272. Suda T, Takubo K, Semenza GL. Metabolic regulation of hematopoietic stem cells in the hypoxic niche. Cell Stem Cell (2011) 9:298-310. doi:10.1016/j.stem. 2011.09.010

273. Zou P, Yoshihara H, Hosokawa K, Tai I, Shinmyozu K, Tsukahara F, et al. p57(Kip2) and p27(Kip1) cooperate to maintain hematopoietic stem cell quiescence through interactions with Hsc70. Cell Stem Cell (2011) 9:247-61. doi:10.1016/j.stem.2011.07.003

274. Mantel C, Messina-Graham S, Broxmeyer HE. Upregulation of nascent mitochondrial biogenesis in mouse hematopoietic stem cells parallels upregulation of CD34 and loss of pluripotency: a potential strategy for reducing oxidative risk in stem cells. Cell Cycle (2010) 9:2008-17. doi:10.4161/cc.9.10. 11733

275. Darzynkiewicz Z, Balazs EA. Genome integrity, stem cells and hyaluronan. Aging (2012) 4:78-88.

276. Simsek T, Kocabas F, Zheng J, Deberardinis RJ, Mahmoud AI, Olson EN, et al. The distinct metabolic profile of hematopoietic stem cells reflects their location in a hypoxic niche. Cell Stem Cell (2010) 7:380-90. doi:10.1016/j.stem. 2010.07.011

277. Kaelin WG Jr, Ratcliffe PJ. Oxygen sensing by metazoans: the central role of the HIF hydroxylase pathway. Mol Cell (2008) 30:393-402. doi:10.1016/j.molcel. 2008.04.009

278. Wheaton WW, Chandel NS. Hypoxia. 2. Hypoxia regulates cellular metabolism. Am J Physiol Cell Physiol (2011) 300:C385-93. doi:10.1152/ ajpcell.00485.2010

279. Miharada K, Karlsson G, Rehn M, Rörby E, Siva K, Cammenga J, et al. Cripto regulates hematopoietic stem cells as a hypoxic-niche-related factor through cell surface receptor GRP78. Cell Stem Cell (2011) 9:330-44. doi:10.1016/j. stem.2011.07.016

280. Takubo K, Goda N, Yamada W, Iriuchishima H, Ikeda E, Kubota Y, et al. Regulation of the HIF-1alpha level is essential for hematopoietic stem cells. Cell Stem Cell (2010) 7:391-402. doi:10.1016/j.stem.2010.06.020

281. Liu J, Cao L, Chen J, Song S, Lee IH, Quijano C, et al. Bmil regulates mitochondrial function and the DNA damage response pathway. Nature (2009) 459:387-92. doi:10.1038/nature08040

282. Nombela-Arrieta C, Pivarnik G, Winkel B, Canty KJ, Harley B, Mahoney $\mathrm{JE}$, et al. Quantitative imaging of haematopoietic stem and progenitor cell localization and hypoxic status in the bone marrow microenvironment. Nat Cell Biol (2013) 15:533-43. doi:10.1038/ncb2730

283. Pietras A, Katz AM, Ekström EJ, Wee B, Halliday JJ, Pitter KL, et al Osteopontin-CD44 signaling in the glioma perivascular niche enhances cancer stem cell phenotypes and promotes aggressive tumor growth. Cell Stem Cell (2014) 14:357-69. doi:10.1016/j.stem.2014.01.005

284. Bartrons R, Caro J. Hypoxia, glucose metabolism and the Warburg's effect. J Bioenerg Biomembr (2007) 39:223-9. doi:10.1007/s10863-007-9080-3

285. Gatenby RA, Gillies RJ. Why do cancers have high aerobic glycolysis? Nat Rev Cancer (2004) 4:891-9. doi:10.1038/nrc1478

286. Das R, Baker D. Macromolecular modeling with rosetta. Annu Rev Biochem (2008) 77:363-82. doi:10.1146/annurev.biochem.77.062906.171838

287. Preston M, Sherman LS. Neural stem cell niches: roles for the hyaluronanbased extracellular matrix. Front Biosci (2011) 3:1165-79. doi:10.2741/218

288. Orian-Rousseau V, Sleeman J. CD44 is a multidomain signaling platform that integrates extracellular matrix cues with growth factor and cytokine signals. Adv Cancer Res (2014) 123:231-54. doi:10.1016/B978-0-12-800092-2. 00009-5

289. Toole BP, Slomiany MG. Hyaluronan: a constitutive regulator of chemoresistance and malignancy in cancer cells. Semin Cancer Biol (2008) 18:244-50. doi:10.1016/j.semcancer.2008.03.009

290. Wang SJ, Bourguignon LY. Hyaluronan and the interaction between CD44 and epidermal growth factor receptor in oncogenic signaling and chemotherapy 
resistance in head and neck cancer. Arch Otolaryngol Head Neck Surg (2006) 132:771-8. doi:10.1001/archotol.132.7.771

291. Sherman LS, Rizvi TA, Karyala S, Ratner N. CD44 enhances neuregulin signaling by Schwann cells. J Cell Biol (2000) 150:1071-84. doi:10.1083/jcb. 150.5.1071

292. Ghatak S, Misra S, Toole BP. Hyaluronan constitutively regulates ErbB2 phosphorylation and signaling complex formation in carcinoma cells. J Biol Chem (2005) 280:8875-83. doi:10.1074/jbc.M410882200

293. Misra S, Hascall VC, De Giovanni C, Markwald RR, Ghatak S. Delivery of CD44 shRNA/nanoparticles within cancer cells: perturbation of hyaluronan/CD44v6 interactions and reduction in adenoma growth in Apc Min/+ MICE. J Biol Chem (2009) 284:12432-46. doi:10.1074/jbc.M806772200

294. Bourguignon LY, Gilad E, Peyrollier K. Heregulin-mediated ErbB2-ERK signaling activates hyaluronan synthases leading to CD44-dependent ovarian tumor cell growth and migration. J Biol Chem (2007) 282:19426-41. doi:10. 1074/jbc.M610054200

295. Orian-Rousseau V, Morrison H, Matzke A, Kastilan T, Pace G, Herrlich P, et al. Hepatocyte growth factor-induced Ras activation requires ERM proteins linked to both CD44v6 and F-actin. Mol Biol Cell (2007) 18:76-83. doi:10. 1091/mbc.E06-08-0674

296. Ni J, Cozzi PJ, Hao JL, Beretov J, Chang L, Duan W, et al. CD44 variant 6 is associated with prostate cancer metastasis and chemo-/radioresistance. Prostate (2014) 74:602-17. doi:10.1002/pros.22775

297. Hasenauer S, Malinger D, Koschut D, Pace G, Matzke A, von Au A, et al. Internalization of Met requires the co-receptor CD44v6 and its link to ERM proteins. PLoS One (2013) 8:e62357. doi:10.1371/journal.pone.0062357

298. Dallas NA, Xia L, Fan F, Gray MJ, Gaur P, van Buren G II, et al. Chemoresistant colorectal cancer cells, the cancer stem cell phenotype, and increased sensitivity to insulin-like growth factor-I receptor inhibition. Cancer Res (2009) 69:1951-7. doi:10.1158/0008-5472.CAN-08-2023

299. Porsch H, Mehić M, Olofsson B, Heldin P, Heldin CH. Platelet-derived growth factor $\beta$-receptor, transforming growth factor $\beta$ type I receptor, and CD44 protein modulate each other's signaling and stability. J Biol Chem (2014) 289:19747-57. doi:10.1074/jbc.M114.547273

300. Mielgo A, van Driel M, Bloem A, Landmann L, Günthert U. A novel antiapoptotic mechanism based on interference of Fas signaling by CD44 variant isoforms. Cell Death Differ (2006) 13:465-77. doi:10.1038/sj.cdd. 4401763

301. Lynch CC, Vargo-Gogola T, Martin MD, Fingleton B, Crawford HC, Matrisian LM. Matrix metalloproteinase 7 mediates mammary epithelial cell tumorigenesis through the ErbB4 receptor. Cancer Res (2007) 67:6760-7. doi:10.1158/ 0008-5472.CAN-07-0026

302. Kivisaari AK, Kallajoki M, Ala-aho R, McGrath JA, Bauer JW, Königová R, et al. Matrix metalloproteinase-7 activates heparin-binding epidermal growth factor-like growth factor in cutaneous squamous cell carcinoma. Br J Dermatol (2010) 163:726-35. doi:10.1111/j.1365-2133.2010.09924.x

303. Buggins AG, Levi A, Gohil S, Fishlock K, Patten PE, Calle Y, et al. Evidence for a macromolecular complex in poor prognosis CLL that contains CD38, $\alpha 4 \beta 1$, CD44 and MMP-9. Br J Haematol (2011) 154:216-22. doi:10.1111/j. 1365-2141.2011.08725.x

304. Ugarte-Berzal E, Bailón E, Amigo-Jiménez I, Albar JP, García-Marco JA, García-Pardo A. A novel CD44-binding peptide from the pro-matrix metalloproteinase- 9 hemopexin domain impairs adhesion and migration of chronic lymphocytic leukemia (CLL) cells. J Biol Chem (2014) 289:15340-9. doi:10.1074/jbc.M114.559187

305. Zarzynska JM. Two FACes of TGF-betal in breast cancer. Mediators Inflamm (2014) 2014:141747. doi:10.1155/2014/141747

306. Takahashi E, Nagano O, Ishimoto T, Yae T, Suzuki Y, Shinoda T, et al. Tumor necrosis factor-alpha regulates transforming growth factor-betadependent epithelial-mesenchymal transition by promoting hyaluronanCD44-moesin interaction. J Biol Chem (2010) 285:4060-73. doi:10.1074/jbc. M109.056523

307. Xu Y, Stamenkovic I, Yu Q. CD44 attenuates activation of the hippo signaling pathway and is a prime therapeutic target for glioblastoma. Cancer Res (2010) 70:2455-64. doi:10.1158/0008-5472.CAN-09-2505

308. Goldie SJ, Mulder KW, Tan DW, Lyons SK, Sims AH, Watt FM. FRMD4A upregulation in human squamous cell carcinoma promotes tumor growth and metastasis and is associated with poor prognosis. Cancer Res (2012) 72:3424-36. doi:10.1158/0008-5472.CAN-12-0423
309. Zhang Y, Xia H, Ge X, Chen Q, Yuan D, Chen Q, et al. CD44 acts through RhoA to regulate YAP signaling. Cell Signal (2014) 26:2504-13. doi:10.1016/j. cellsig.2014.07.031

310. Wang Z, Wu Y, Wang H, Zhang Y, Mei L, Fang X, et al. Interplay of mevalonate and hippo pathways regulates RHAMM transcription via YAP to modulate breast cancer cell motility. Proc Natl Acad Sci U S A (2014) 111:E89-98. doi:10.1073/pnas.1319190110

311. Zhao H, Tanaka T, Mitlitski V, Heeter J, Balazs EA, Darzynkiewicz Z. Protective effect of hyaluronate on oxidative DNA damage in WI-38 and A549 cells. Int J Oncol (2008) 32:1159-67.

312. Thankamony SP, Knudson W. Acylation of CD44 and its association with lipid rafts are required for receptor and hyaluronan endocytosis. J Biol Chem (2006) 281:34601-9. doi:10.1074/jbc.M601530200

313. Campo GM, Avenoso A, Campo S, D’Ascola A, Ferlazzo AM, Calatroni A. Reduction of DNA fragmentation and hydroxyl radical production by hyaluronic acid and chondroitin-4-sulphate in iron plus ascorbate-induced oxidative stress in fibroblast cultures. Free Radic Res (2004) 38:601-11. doi:10. 1080/10715760410001694017

314. Bourguignon LY, Earle C, Wong G, Spevak CC, Krueger K. Stem cell marker (Nanog) and Stat-3 signaling promote microRNA-21 expression and chemoresistance in hyaluronan/CD44-activated head and neck squamous cell carcinoma cells. Oncogene (2012) 31:149-60. doi:10.1038/onc.2011.222

315. Kathawala RJ, Gupta P, Ashby CR Jr, Chen Z. The modulation of ABC transporter-mediated multidrug resistance in cancer: a review of the past decade. Drug Resist Updat (2014) pii:78-78. doi:10.1016/j.drup.2014.11.002

316. Misra S, Ghatak S, Toole BP. Regulation of MDR1 expression and drug resistance by a positive feedback loop involving hyaluronan, phosphoinositide 3-kinase, and ErbB2. J Biol Chem (2005) 280:20310-5. doi:10.1074/jbc. M500737200

317. Liu CM, Chang $\mathrm{CH}, \mathrm{Yu} \mathrm{CH}$, Hsu CC, Huang LL. Hyaluronan substratum induces multidrug resistance in human mesenchymal stem cells via CD44 signaling. Cell Tissue Res (2009) 336:465-75. doi:10.1007/s00441-009-0780-3

318. Bourguignon LY, Xia W, Wong G. Hyaluronan-mediated CD44 interaction with p300 and SIRT1 regulates beta-catenin signaling and NFkappaB-specific transcription activity leading to MDR1 and Bcl-xL gene expression and chemoresistance in breast tumor cells. J Biol Chem (2009) 284:2657-71. doi:10. 1074/jbc.M806708200

319. Slomiany MG, Dai L, Bomar PA, Knackstedt TJ, Kranc DA, Tolliver L, et al. Abrogating drug resistance in malignant peripheral nerve sheath tumors by disrupting hyaluronan-CD44 interactions with small hyaluronan oligosaccharides. Cancer Res (2009) 69:4992-8. doi:10.1158/0008-5472.CAN-09-0143

320. Negi LM, Talegaonkar S, Jaggi M, Ahmad FJ, Iqbal Z, Khar RK. Role of CD44 in tumour progression and strategies for targeting. J Drug Target (2012) 20:561-73. doi:10.3109/1061186X.2012.702767

321. Midgley AC, Bowen T. Analysis of human hyaluronan synthase gene transcriptional regulation and downstream hyaluronan cell surface receptor mobility in myofibroblast differentiation. Methods Mol Biol (2015) 1229:605-18. doi:10.1007/978-1-4939-1714-3_47

322. Sebens $\mathrm{S}$, Schafer $\mathrm{H}$. The tumor stroma as mediator of drug resistance - a potential target to improve cancer therapy? Curr Pharm Biotechnol (2012) 13:2259-72. doi:10.2174/138920112802501999

323. Lokeshwar VB, Mirza S, Jordan A. Targeting hyaluronic acid family for cancer chemoprevention and therapy. Adv Cancer Res (2014) 123:35-65. doi:10.1016/ B978-0-12-800092-2.00002-2

324. Skandalis SS, Gialeli C, Theocharis AD, Karamanos NK. Advances and advantages of nanomedicine in the pharmacological targeting of hyaluronan-CD44 interactions and signaling in cancer. Adv Cancer Res (2014) 123:277-317. doi:10.1016/B978-0-12-800092-2.00011-3

325. Misaghian N, Ligresti G, Steelman LS, Bertrand FE, Bäsecke J, Libra M, et al. Targeting the leukemic stem cell: the Holy Grail of leukemia therapy. Leukemia (2009) 23:25-42. doi:10.1038/leu.2008.246

326. ten Cate B, de Bruyn M, Wei Y, Bremer E, Helfrich W. Targeted elimination of leukemia stem cells; a new therapeutic approach in hemato-oncology. Curr Drug Targets (2010) 11:95-110. doi:10.2174/138945010790031063

327. Tabarkiewicz J, Giannopoulos K. Definition of a target for immunotherapy and results of the first peptide vaccination study in chronic lymphocytic leukemia. Transplant Proc (2010) 42:3293-6. doi:10.1016/j.transproceed.2010.07.022

328. Majeti R. Monoclonal antibody therapy directed against human acute myeloid leukemia stem cells. Oncogene (2011) 30:1009-19. doi:10.1038/onc.2010.511 
329. Konopleva MY, Jordan CT. Leukemia stem cells and microenvironment: biology and therapeutic targeting. J Clin Oncol (2011) 29:591-9. doi:10.1200/ JCO.2010.31.0904

330. Brayer JB, Pinilla-Ibarz J. Developing strategies in the immunotherapy of leukemias. Cancer Control (2013) 20:49-59.

331. Bourguignon LY, Gunja-Smith Z, Iida N, Zhu HB, Young LJ, Muller WJ, et al. CD44v(3,8-10) is involved in cytoskeleton-mediated tumor cell migration and matrix metalloproteinase (MMP-9) association in metastatic breast cancer cells. J Cell Physiol (1998) 176:206-15. doi:10.1002/(SICI)1097-4652(199807) 176:1<206::AID-JCP22>3.0.CO;2-3

332. D'Arena G, Calapai G, Deaglio S. Anti-CD44 mAb for the treatment of Bcell chronic lymphocytic leukemia and other hematological malignancies: evaluation of WO2013063498. Expert Opin Ther Pat (2014) 24:821-8. doi:10. $1517 / 13543776.2014 .915942$

Conflict of Interest Statement: The author declares that the research was conducted in the absence of any commercial or financial relationships that could be construed as a potential conflict of interest.

Copyright (c) 2015 Zöller. This is an open-access article distributed under the terms of the Creative Commons Attribution License (CC BY). The use, distribution or reproduction in other forums is permitted, provided the original author(s) or licensor are credited and that the original publication in this journal is cited, in accordance with accepted academic practice. No use, distribution or reproduction is permitted which does not comply with these terms. 